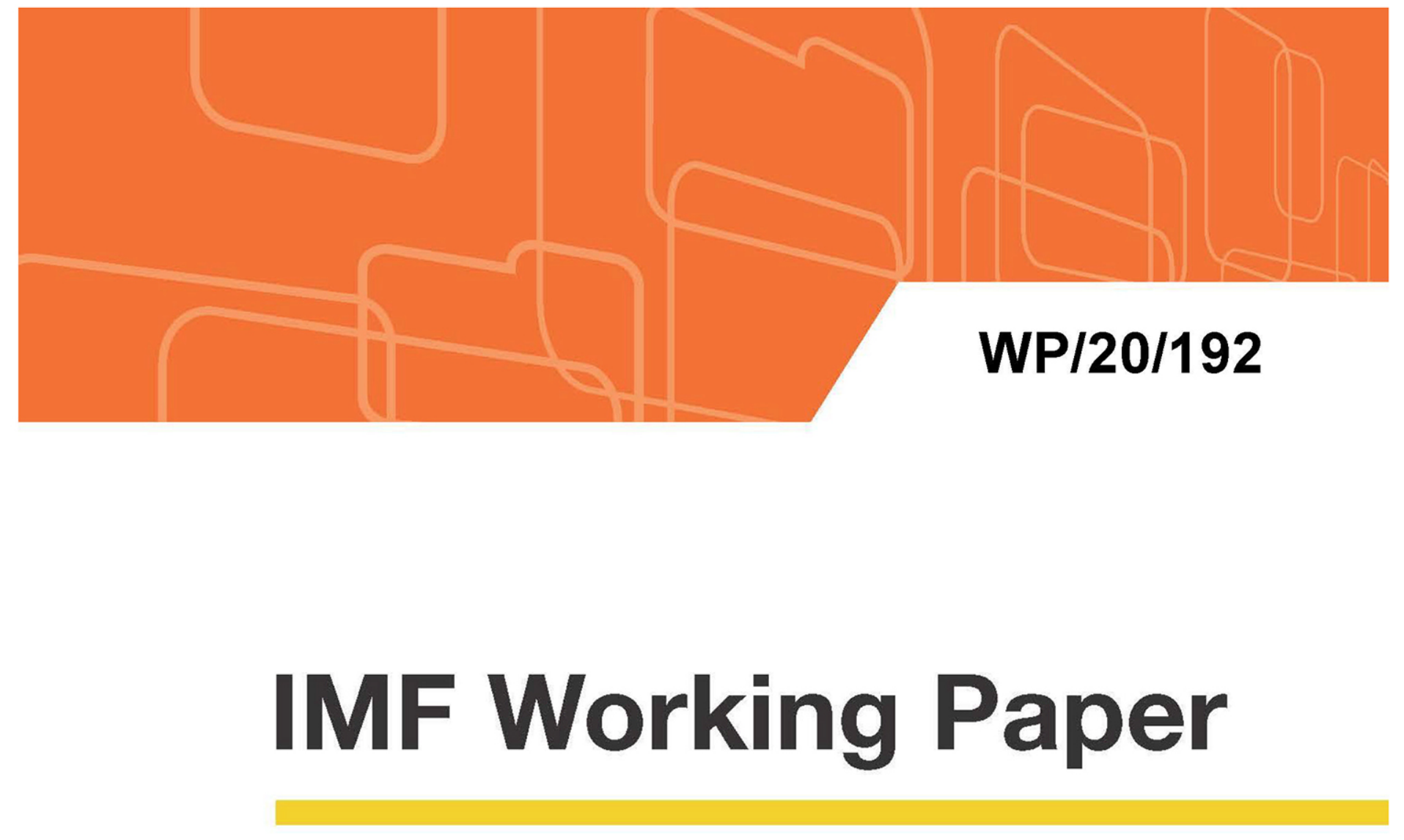

\title{
Benchmark-Driven Investments in Emerging Market Bond Markets: Taking Stock
}

by Serkan Arslanalp, Dimitris Drakopoulos, Rohit Goel, and Robin Koepke

IMF Working Papers describe research in progress by the author(s) and are published to elicit comments and to encourage debate. The views expressed in IMF Working Papers are those of the author(s) and do not necessarily represent the views of the IMF, its Executive Board, or IMF management.

$$
\text { I N T E R N A T I O N A L M O N E TAR Y F U N D }
$$




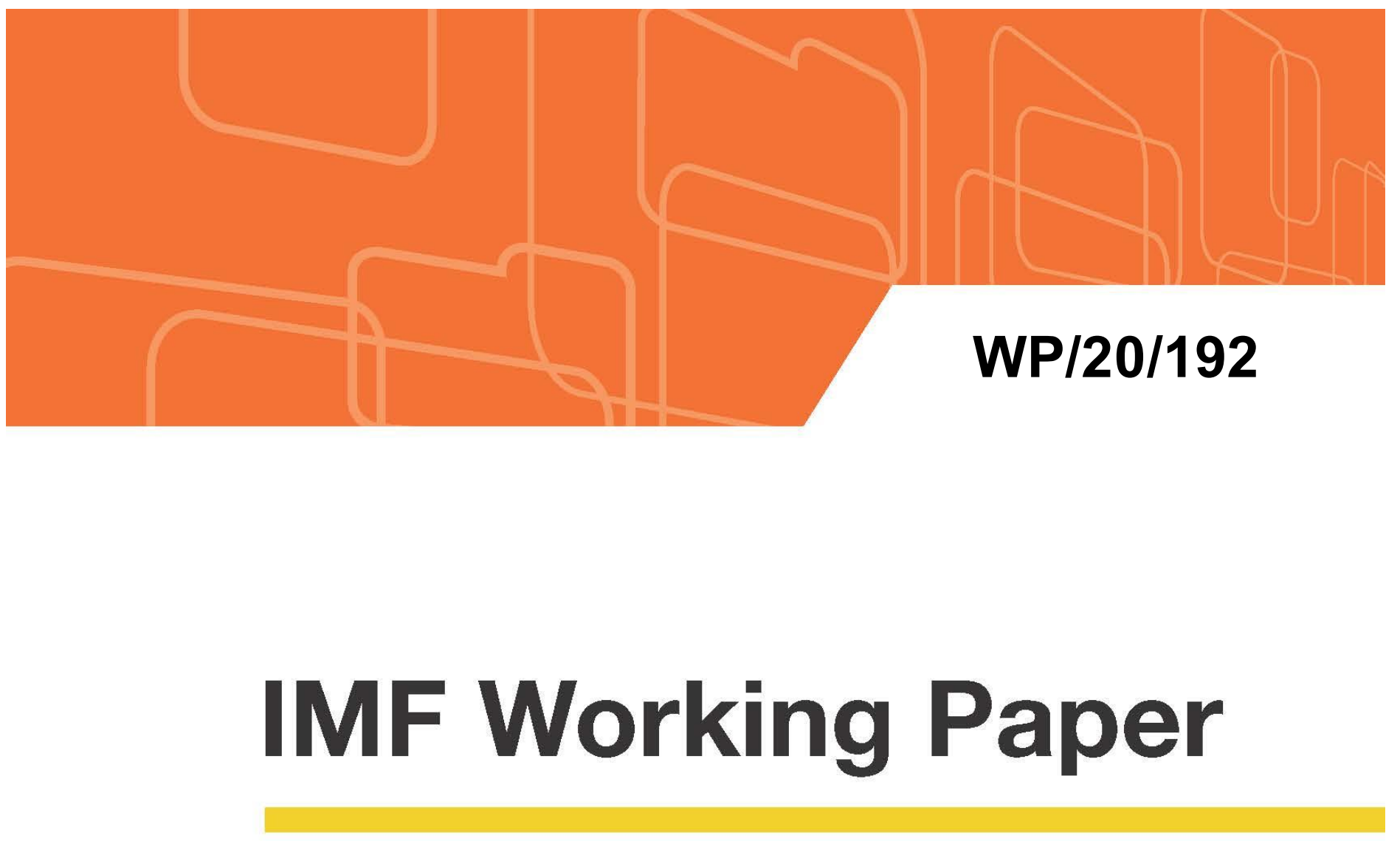

\section{Benchmark-Driven Investments in Emerging Market Bond Markets: Taking Stock}

by Serkan Arslanalp, Dimitris Drakopoulos, Rohit Goel, and Robin Koepke

IMF Working Papers describe research in progress by the author(s) and are published to elicit comments and to encourage debate. The views expressed in IMF Working Papers are those of the author(s) and do not necessarily represent the views of the IMF, its Executive Board, or IMF management. 


\title{
IMF Working Paper
}

Asia and Pacific Department

\section{Benchmark-Driven Investments in Emerging Market Bond Markets: Taking Stock Prepared by Serkan Arslanalp, Dimitris Drakopoulos, Rohit Goel, and Robin Koepke ${ }^{1}$}

\author{
Authorized for distribution by Thomas F. Helbling
}

September 2020

\begin{abstract}
IMF Working Papers describe research in progress by the author(s) and are published to elicit comments and to encourage debate. The views expressed in IMF Working Papers are those of the author(s) and do not necessarily represent the views of the IMF, its Execu tive Board, or IMF management.
\end{abstract}

\begin{abstract}
This paper reviews the role of benchmark-driven investments in EM local bond markets. We provide an overview of how key EM bond benchmark indices are constructed, how they affect the behavior of investment funds, and what are the likely implications for capital flows and policy-making. Several methods are presented suggesting that the amount of assets benchmarked against widely followed EM local-currency bond indices have risen fivefold since the mid-2000s to around $\$ 300$ billion. Our review suggests that the benefits of index membership may be tempered by portfolio outflow risks for some countries. This is because benchmark-driven investments may increase the importance of external factors at the expense of domestic factors, raising the risks of outflows unrelated to recipient country fundamentals. Some countries may be disproportionately exposed to these risks, reflecting the way the indices are constructed.
\end{abstract}

JEL Classification Numbers: F3, F4, G01, G11

Keywords: Capital flows, portfolio choice, push and pull, benchmarks

Author's E-Mail Address: SArslanalp@,imf.org; DDrakopoulos@imf.org; RGoel@imf.org; RKoepke@imf.org

\footnotetext{
${ }^{1}$ Some of the results presented in this pa per were featured in the IMF's April 2019 Global Financial Stability Report. Part of the paper a lso builds on Arsla nalp and Tsuda (2015) and presents updated results. The authors are gra teful for very helpful comments and suggestions by Eugenio Cerutti, Sa lih Fendoglu, Swarnali Ahmed Hannan, Thomas Helbling, Ken Miyajima, Evan Papageorgiou, Andrea Presbitero, Michael Trounce, Takahiro Tsuda, Jeffrey Willia ms, Tomas Willia ms and participants at the IMF STA Innovation Talks seminar. Nong Jotika sthira provided outstanding a dministrative and editorial a ssistance.
} 
I. Introduction

II. What Are Benchmark-Driven Investments and What Are the Implications for Capital Flows?

A. What Are Key EM Bond Benchmarks and How Are they Constructed? ................. $\underline{6}$

B. How Do Benchmark Indices Affect the Behavior of Investment Funds? ................. $\underline{8}$

C. What Are Potential Implications for Capital Flows? ....................................

III. How Large Are Benchmark-Driven Investments in EM Bond Markets?....................11

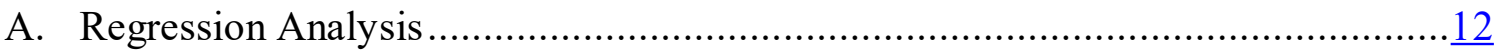

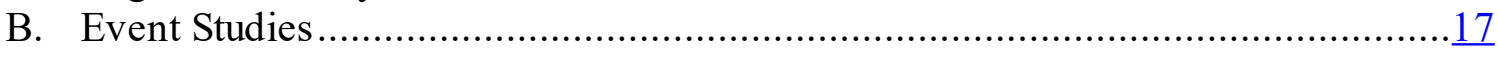

IV. How Sensitive Are Benchmark-Driven Investments to Global Factors?.....................19

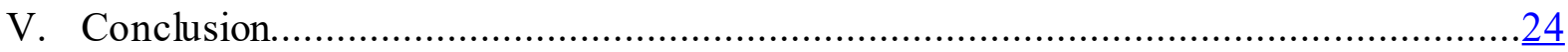

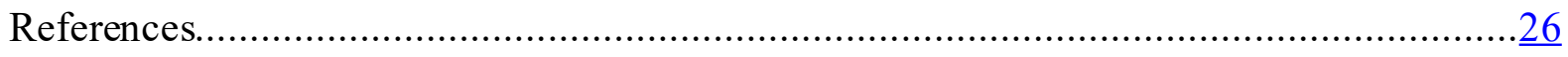

Figures

1. Correlation Coefficients of EM Local Currency Bond Flows ................................. 4

2. Estimates of Benchmark-Driven Investors .................................................... $\frac{5}{5}$

3. Portfolio Flows Proxies................................................................................. 5

4. Portfolio Outflows During COVID-19 and Country Weights in JPM GBI-EM Global

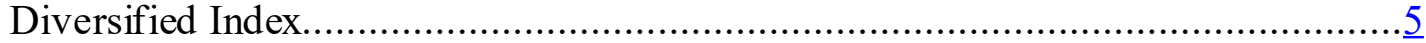

5. Emerging Market Benchmark-Driven versus Unconstrained Investors ........................ $\underline{6}$

6. Some Emerging Market Issuers Receive a Major Boost from BDI Holders due to Index Rules.............................................................................

7. The Rise of Benchmark Investing in Emerging Markets and the Declining

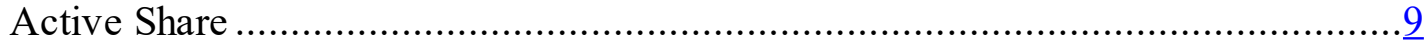

8. The Financial Accelerator and External Factors............................................. 10

9. The Rise of Benchmark-Driven Investing in EM Bond Markets.............................12

10. Emerging Market Local-Currency Government Debt Securities, End-2019 ................14

11. Emerging Market Local-Currency Government Debt Markets: Country

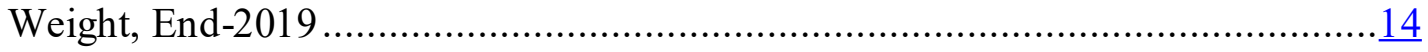

12. Foreign Holdings of Emerging Market Local-Currency Government Debt, 2010-2020:Q2

13. Emerging Market Local-Currency Government Debt Markets: Type of

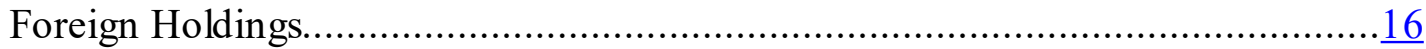

14. Country Level Estimates of Benchmark-Driven Investors................................. 16

15. Sensitivity of Flows to Extemal Factors........................................................ 21

16. Local Bond Yields Become More Correlated After Benchmark Inclusion Events .........23 
Tables

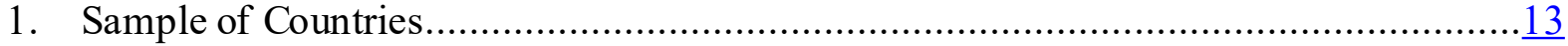

2. Regression Results of the Constrained Least Squares Estimation ..............................15

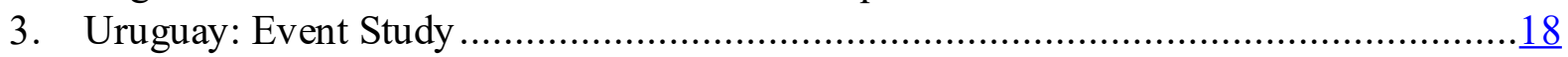

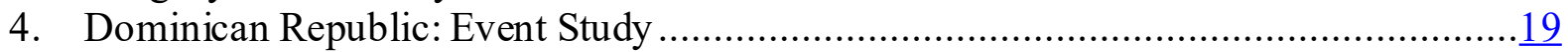

5. Regression Results on Sensitivity to Global Factors ..............................................22

Annexes

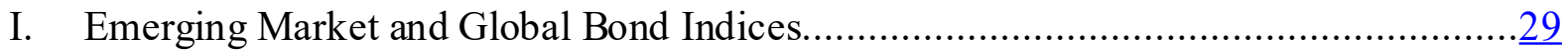

II. China's Inclusion in Benchmark Bond Indices ...................................................

III. Emerging Market Local Currency Government Debt: Foreign Holdings, 2010-20 ........32 


\section{INTRODUCTION}

Benchmark driven investments (BDI) have received growing attention in the recent literature on portfolio flows to emerging markets. An investment is benchmark-driven to the extent that its portfolio allocation across countries is guided by the country weights in a benchmark index (IMF 2019, Arslanalp and Tsuda 2015). A number of influential studies have found evidence that investment benchmarks are increasingly shaping portfolio allocation dynamics in emerging market (EM) countries. For example, Raddatz and others (2017) find that 70 percent of country allocations of investment mutual funds are influenced by benchmark indices.

The growing role of benchmark-driven investments appears to reflect the confluence of several factors and may be contributing to more synchronized portfolio flows. These factors include rising assets under management of passive funds, increasing number of active funds "hugging" the index, and a growing number of countries represented in the benchmark indices. Together, these factors may have contributed to more correlated portfolio flows to countries included in benchmarks indices. For example,

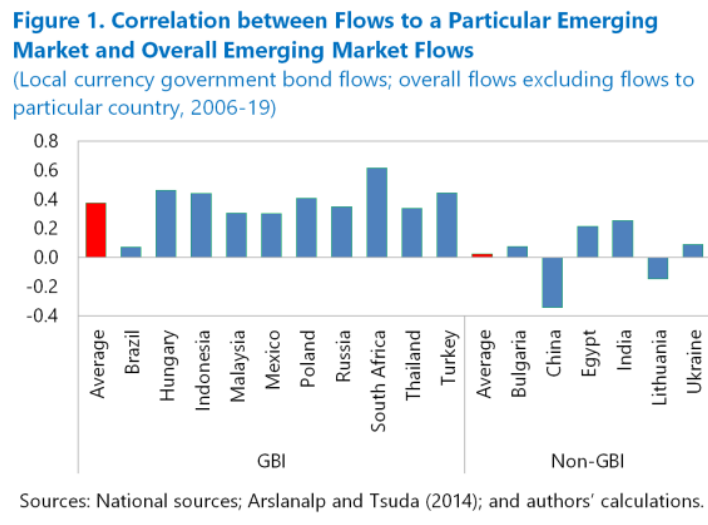

Figure 1. Correlation between Flows to a Particular Emerging Market and Overall Emerging Market Flows

(Local currency government bond flows; overall flows excluding flows to particular country, 2006-19) 0.8

Sources: National sources; Arslanalp and Tsuda (2014); and authors' calculations. portfolio flows to EM local bond markets have traditionally been much more synchronized for countries in a benchmark index (the J.P Morgan GBI-EM Global) than those that were not in the index (Figure 1).

A burgeoning literature suggests that the growing role of benchmark-driven investments entails both benefits and risks for portfolio flows to EMs. On the upside, inclusion in major benchmark indices provides countries with access to a larger and more diverse pool of external financing (Sienaert 2012). On the downside, benchmark-driven investments may raise the sensitivity of portfolio flows to global factors and, more generally, to factors common to EMs included in benchmark indices (IMF 2019, Arslanalp and Tsuda 2015). This is because benchmark-driven investments are investment in EMs as an asset class, focusing mainly on factors that affect EMs as a group, rather than on country-specific developments. As a result, benchmark-driven portfolio flows may be more sensitive to common factors and therefore more correlated across countries.

The study by Raddatz and others (2017) empirically demonstrates that benchmark indices affect asset allocations, capital flows, and asset returns of international mutual funds in a statistically significant and economically important way. The study shows that the use of benchmarks generates pricing and flow distortions that represent deviations from the theoretical predictions of standard models (such as the CAPM). Related research shows that the use of benchmarks can give rise to correlated behavior on the part of even "actively" managed funds (Miyajima and Shim 2014) and that EMs with higher shares of financing from investment funds are more sensitive to external/push factors (Cerutti and others 2015). 
Building on this literature, this paper takes stock of the rise of benchmark-driven investments in EM bond markets. We focus particularly on local currency government bonds - the single largest segment of EM bond markets. First, we provide an overview of how key EM bond benchmark indices are constructed, how they affect the behavior of investment funds, and what are the likely implications for capital flows dynamics. Second, we provide up-to-date estimates of the size of benchmark-driven investments in local EM bond markets, estimated at around \$300 billion as of end 2019 before the COVID-19 shock in early 2020 (Figure 2). Third, we provide empirical results demonstrating the heightened sensitivity of benchmark-driven investments to external factors, which leads to an elevated correlation of such flows across countries.

During the COVID-19 pandemic, the combined effect of this heightened sensitivity and the growing assets under management appears to have contributed to the record outflows of foreign portfolio capital from emerging markets (IMF 2020) (Figure 3). In this episode, portfolio outflows from local currency bond markets were quite strongly correlated with the weight of the country in the GBI-EM benchmark index, suggesting that benchmark-driven investors may have played a significant role in driving the reversal of portfolio flows (Figure 4).
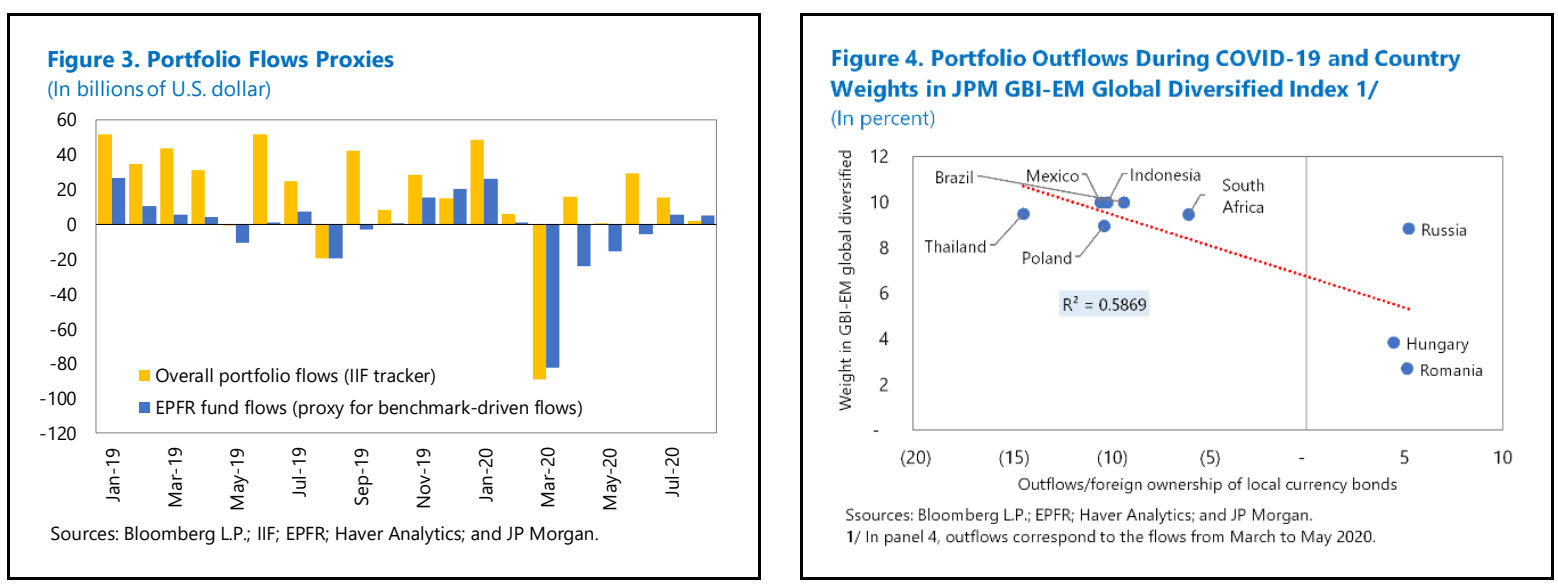

Overall, the picture that emerges from our review is that benchmark-driven investments are changing the landscape for EM bond markets, with important implications for capital flows dynamics. Different investor types exhibit fundamentally different behaviors in deciding their portfolio allocations, and different countries exhibit widely different investor bases. As a result, the same kinds of external and domestic shocks can prompt different capital flow responses in different countries, in turn, shaping the way such shocks are transmitted to the domestic economy. 
The rest of this paper is organized as follows. Section 2 explains key concepts for benchmark-driven investments and its implications for capital flows. Section 3 provides country-level estimates of benchmark-driven investments through regression analysis and event studies. Section 4 discusses the effects of benchmark-driven investments on capital flows dynamics. Section 5 provides concluding remarks.

\section{WHAT ARE BENCHMARK-DRIVEN INVESTMENTS AND WHAT ARE THE IMPLICATIONS FOR CAPITAL FLOWS?}

Benchmark-driven investments come about mainly in the context of investment funds, most of which use benchmark indices to guide their portfolio allocation. Investment funds vary in the degree to which they are benchmark-driven in that some follow the country weights of their benchmark more closely than others. Passive investment funds explicitly aim to replicate the performance of their benchmark, while active funds deviate from their benchmarks to varying degrees as fund managers try to outperform their respective benchmarks (Figure 5). By contrast, unconstrained funds choose portfolio allocations irrespective of benchmark indices. It is worth noting that the ultimate investors of benchmark-driven funds can be retail or institutional investors, though retail investors generally have only limited access to unconstrained funds.

Figure 5. Emerging Market Benchmark-Driven versus Unconstrained Investments

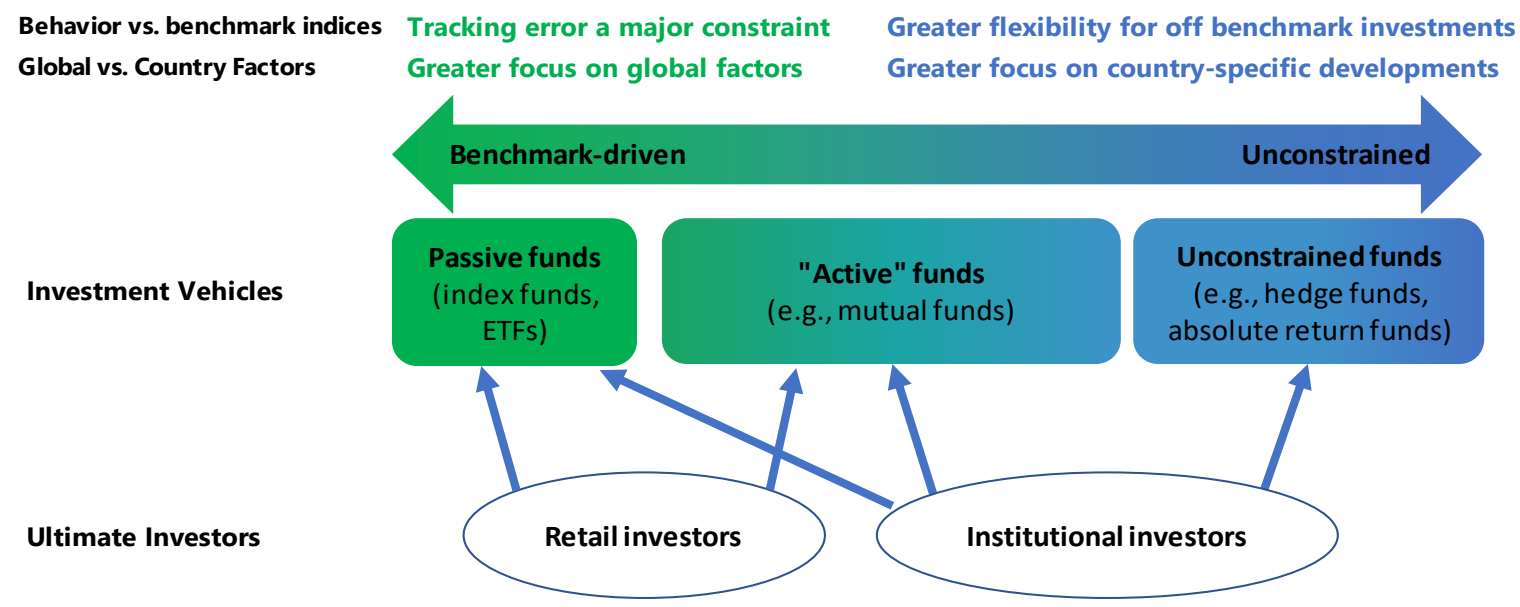

Source: Author's illustration.

\section{A. What are Key EM Bond Benchmarks and How are They Constructed?}

Among the multitude of investment funds focused on emerging market local bonds, most are benchmarked to a small number of indices. The most widely followed benchmark indices for emerging market bonds are the J.P. Morgan Emerging Market Bond Index (EMBIG; for dollar-denominated bonds) and the J.P. Morgan Government Bond Index-Emerging Markets (GBI-EM; for local currency bonds), both of which come in several variants. Benchmark driven investments discussed in this paper primarily refer to investment funds benchmarked to these two indices (as discussed in greater details in Annex I). 
The number of countries represented in benchmark indices has grown substantially over the years, especially among emerging markets. Since 2007, the number of countries in the EMBIG has doubled to more than 70 with the inclusion of many countries that have issued in international bond markets for the first time. In addition, the growing size and liquidity of local bond markets in many emerging markets have allowed the number of countries in the GBI EM to increase from 12 to 18 . By contrast, although many EMs have earned investment grade status from rating agencies, the number of countries with local currency debt represented in global investment grade bond indices has been relatively stable, given the more demanding investability criteria of these indices (Annex I).

Due to the way indices are constructed, some countries are disproportionately exposed to benchmark-driven investors. This reflects both index inclusion rules and discretionary choices of index providers. Different inclusion criteria for each index lead to varying compositions of investor types, exposing issuers to diverse portfolio flow dynamics. Inclusion criteria help determine the universe of investors attracted to a given country (Annex II). In particular:

- Global bond benchmarks: Investors tracking global bond benchmarks, are less likely to react to risks specific to EMs, given that these countries represent only a small fraction of the total index and hence make a small contribution to their overall returns. However, EMs that are part of global bond benchmarks have a larger share of rating-sensitive investors, given that these indices use ratings as criteria for index inclusion/exclusion. As a result, they can face large selling from benchmark-driven investors in the event of a loss of investment grade status (e.g., Pemex and South Africa in April 2020, Petrobras in September 2015). ${ }^{2}$

- EM bond benchmarks: Contrary to global bond benchmarks, the most widely used EM bond benchmarks are not rating sensitive and bonds remain eligible as long as the liquidity criteria are satisfied. This may have a stabilizing effect on portfolio dynamics given the procyclical nature of credit ratings that can aggravate crisis episodes (Ferri, Liu, and Stiglitz 2003).

\footnotetext{
${ }^{2}$ In some cases, global bond indices can a lso play an important role in bringing capital to EMs. Sienaert (2012) provides some evidence that Mexico and South Africa's inclusion in the FTSE World Government Bond Index (WGBI) triggered a significant increase in net foreign purchases of local currency bonds during their inclu sion.
} 
An important feature of the most commonly followed version of EM benchmarks is a weighting method that reduces the weight of larger issuers and redistributes the excess to smaller countries. This can create distortions for asset allocation portfolio flows. For local currency government bonds, for example, these "diversified" indices limit the maximum weight to 10 percent, which leads to more concentrated positions of benchmark driven investors in some smaller issuers. For example, Brazil's weight is capped

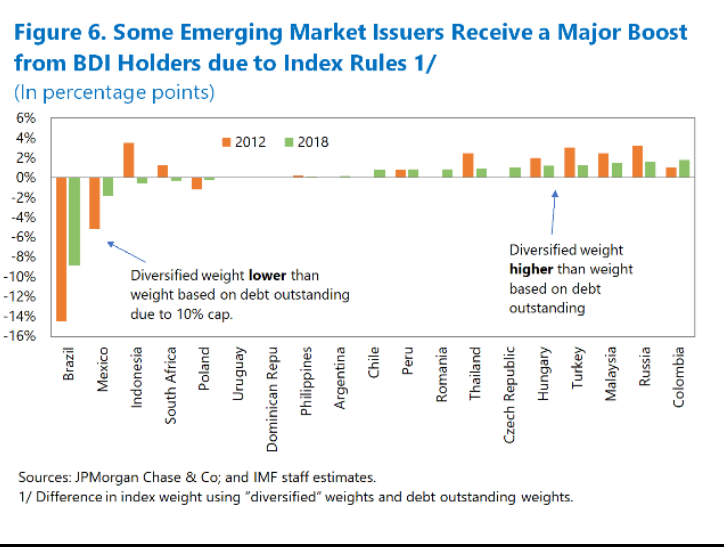
8 percentage points lower than it would be under the market capitalization weights used in global benchmarks (Figure 5). On the other hand, smaller issuers such as Colombia, Hungary and Peru see an increase in their weights by 1 to 2 percent. As the index is tracked by an estimated $\$ 300$ billion (see next section), a 2 percentage points higher weight would mean $\$ 6$ billion additional benchmark driven investments due to index rules, which can be substantial for smaller countries.

Index inclusion decisions by index providers can also manifest at the security level depending on whether certain securities meet liquidity criteria. One recent example of a large liquidity related weight change is Malaysia's weight reduction from in GBI-EM GD from 10 percent on February 2016 to 6 percent on August 2017. Part of this reduction was due to measures taken by the authorities in December 2016 that, in the view of J.P Morgan, impacted the liquidity of Malaysian government debt securities due to changes in the non-deliverable forward (NDF) market (J.P. Morgan, 2017). ${ }^{3}$ Such a weight reduction, unlike reductions driven by market value, would naturally lead to a reduction of benchmark driven investors who may need to mechanically rebalance their positions.

Benchmark effects can affect countries due to the inclusion of new countries in the benchmark index. Index inclusion decisions can lead to substantial rebalancing of portfolios and can alter the risk characteristics of the asset class. For example, J.P. Morgan recently included China in the GBI-EM Global index (Annex II). Over the transition period, in addition to boosting flows to the Chinese bond market, this will also lead to an index weight reduction for other countries and consequently to some rebalancing by benchmark-driven funds.

\footnotetext{
${ }^{3}$ In May 2017, the index provider noted that "changes in the NDF ha ve impacted MGS liquidity resulting in reduced weight over the past six months." The reduction in Malaysia's index weight was also due to other rea son such as lower net issuance relative to other markets and inclusion of new bond markets in the index (see also Lu and Yakovlev, 2018).
} 


\section{B. How Do Benchmark Indices Affect the Behavior of Investment Funds?}

Previous work has shown that even supposedly active investment funds tend to follow their benchmark relatively closely. This is evident in standard metrics of fund behavior, such as the "active share" of a fund, which is defined as the sum of the absolute value of deviations of the fund's country weights from those of the benchmark (Cremers and Petajisto, 2009). Miyajima and Shim (2014) show that the median "active share" is only 17 percent, among active EM local-currency bond funds tracked by the Emerging Portfolio Fund Research (EPFR) Global. This indicates a very high (83 percent) overlap in country weights between fund portfolios and the relevant benchmark. Accordingly, the authors label funds with an active share of 0-10 percent as "closet index" funds, and funds with an active share of 10-20 percent as "weakly active" funds. Based on this definition, they show that nearly 70 percent of actively managed EM bond funds tracked by EPFR Global are either a "closet index" or a "weakly active" funds - that is, benchmark driven.

We confirm that this trend has remained in place by calculating the active share for EM local currency bond funds. We find that the active share has been declining steadily since 2008 among EM local currency bond funds tracked by the EPFR (Figure 7, pane12). This finding is corroborated using other metrics, such as the average tracking error - the difference between the return of a fund and its benchmark - of EM local bond funds (IMF, 2019). The trend that active funds are becoming more passive may partly be explained by underperformance of active funds over the last decade as well as the trend towards low-cost funds by retail investors.

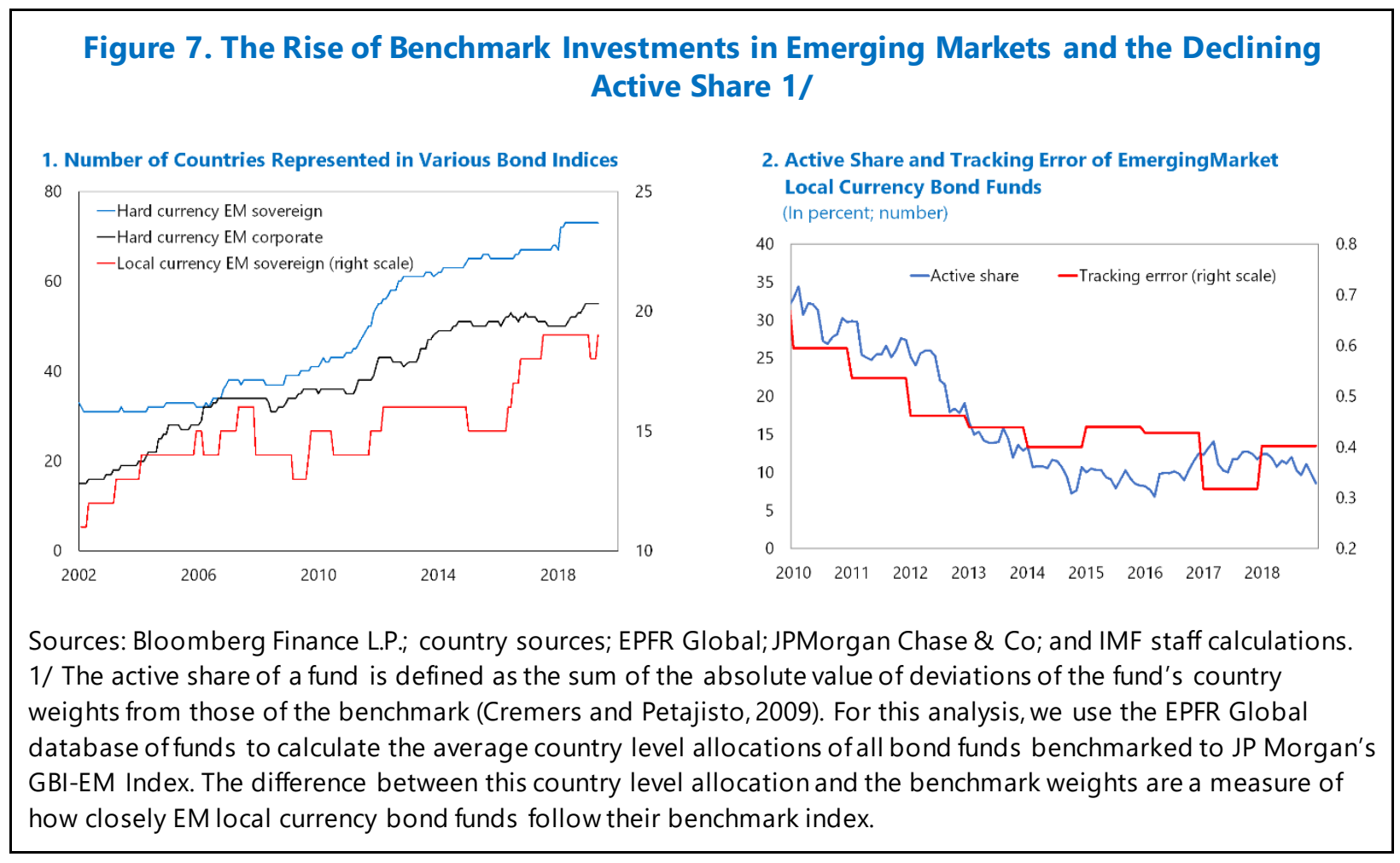




\section{What are Potential Implications for Capital Flows?}

Previous work has shown that the role of benchmark-driven investments results in a higher degree of similarity in cross-country asset allocations and capital flows, especially when comparing emerging market investors. For example, Raddatz and others (2017) find that benchmarks can have significant effects on international investments and affect capital flows through both direct and indirect channels. In particular, the authors find that benchmarks explain, on average, around 70 percent of country allocations even after controlling for macroeconomic, industry, and country-specific effects. They define the "benchmark effect" as the channels through which "prominent international equity and bond market indices affect asset allocations and capital flows across countries," differentiating it from the role domestic and external factors play in country allocations.

Similarly, Cerutti and others (2019) find that EMs relying more on global mutual funds are more sensitive to external factors in terms of their gross equity and bond inflows. Recipient market liquidity and inclusion in global benchmark indices also increase sensitivities. They also find little robust evidence that institutional and macroeconomic fundamentals dampen sensitivities. At the same time, in a multiple event study, Pandolfi and Williams (2020) show that index inclusion events lead to significant declines in government bond yields and to appreciation of the domestic currencies.

Relatedly, studies have shown that mutual funds can propagate shocks through several channels, including (i) directly via their holdings (Broner, Gelos, and Reinhart, 2006), (ii) indirectly through overlapping ownership of emerging and advanced economies (Jotikasthira and others, 2012); and (iii) via fire sales (Coval and Stafford, 2007). Miyajima and Shim (2014) specifically explore the use of benchmark indices in EMs. They find that the use of benchmarks can give rise to correlated behavior on the part of even "actively" managed funds. They argue that managers of those funds tend to be evaluated by whether the returns of their investments match or exceed those of a particular index. As a result, although active managers do not replicate the portfolio weights of the benchmark, the career risk of short-term underperformance against their peers can induce them to form similar portfolios or to "hug" their benchmarks, increasing correlation of asset managers' portfolio choices.

For policymakers, two contrasting implications from these effects are worth highlighting. On the one hand, a rising share of benchmark-driven investments can be a source of vulnerability because it increases the country's exposure to external shocks, as capital flows become more sensitive to external conditions (Miyajima and Shim 2014, Raddatz and others 2017). On the other hand, a rising share of benchmark-driven investments can be a source of resilience because it reduces the country's exposure to domestic shocks, as capital flows become less sensitive to deteriorating country conditions/fundamentals.

Figure 8 illustrates these two effects based on a stylized financial accelerator framework (Bernanke and others 1994). The financial accelerator describes the self-reinforcing feedback loop between economic fundamentals and financial conditions. For example, deteriorating economic conditions result in higher credit spreads as lenders become more concerned about borrowers' creditworthiness (feedback loop A below). This tightening in financial conditions further slows the economy (feedback loop B). In emerging markets, external factors play an 
additional important role in affecting domestic financial conditions. For example, a jump in global risk aversion that tightens external financial conditions will also result in deteriorating domestic financial conditions (feedback loop C). Severe financial distress typically arises through some combination of domestic and external shocks, which set off a vicious cycle of deteriorating economic and financial conditions (Kamin and others, 2001).

Figure 8. The Financial Accelerator and External Factors 1/

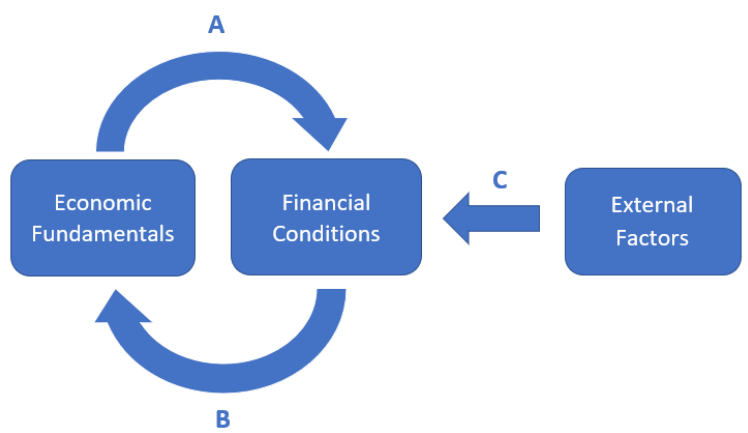

Source: Author's illustration.

1/ For illustration purpose, this schematic focuses on a small number of economic factors and relationships. For example, external factors may also affect economic fundamentals directly.

In this framework, a low share of benchmark-driven investments means that foreign portfolio flows are highly responsive to domestic factors (i.e., feedback loop A is relatively strong), but not so responsive to external developments (i.e., feedback loop C is relatively weak). An example would be Argentina, which has only a small weight in EM local bond indices and most of its local debt is owned by unconstrained institutional investors.

Conversely, a high share of benchmark-driven investors means that portfolio flows are less responsive to domestic factors (i.e., feedback loop A is relatively weak), but highly responsive to external developments (i.e., feedback loop C is strong). An example would be Colombia, which has a relatively high weight in the EM local bond indices and whose foreign investor base has been relatively stable despite several domestic shocks.

\section{HOW LARGE ARE BENCHMARK-DRIVEN INVESTMENTS IN EM BOND MARKETS?}

The past decade has seen a remarkable rise in the importance of asset managers for portfolio flows to emerging markets and a consequent increase in the importance of various benchmarks. Over that period, foreign investors doubled their holdings of EM government debt to more than $\$ 1.5$ trillion. More than 60 percent of this increase came from foreign asset managers (Figure 9, panel 1). In this section, we discuss the magnitude foreign bond holdings of benchmark driven investors, particularly in the local currency bond market.

A useful concept for gauging the size of benchmark driven investments is to think of them as a pool of money that is allocated purely according to the index weights. This concept has the advantage that it can be used to calculate the dollar amount of a portfolio shift corresponding to a change in the benchmark index, which is highly relevant from a policy perspective because it helps assess and predict shifts in the availability of external financing. Specifically, based on this concept, a change in the weights of the underlying benchmark would trigger a reallocation of funds equivalent to the percentage change in the index weight times the dollar amount of benchmark-driven investments. For example, if the weight of country A in the index were reduced from 10 to 9 percent (say, due to the inclusion of 
another country), and assuming a pool of benchmark-driven investments of $\$ 100$ billion, one would expect a reallocation of $\$ 1$ billion away from country A.

In practice, there is much uncertainty about the holdings of benchmark driven investors. One reason is that funds follow benchmark indices to varying degrees. Another reason is that data providers like EPFR can only report assets under management (AUM) of those mutual funds and ETFs that reveal their holdings. Moreover, these vehicles are mostly used by retail investors, whereas most AUMs for major asset managers are from institutional investors (e.g., pension funds, endowments). These institutional investors may be invested in similar strategies as the mutual funds but details on their portfolio holdings at the country and security level are very limited.

Some information about the magnitude of benchmark driven investments can be gained from surveys of index providers on the amount of funds tracking their index, but these surveys also have shortcomings. For example, J.P. Morgan provides a monthly investor survey on AUM tracking its EM bond indices (Figure 9, panel 2). However, the survey likely does not fully capture AUM that are invested with mixed mandates and use a combination of benchmarks (e.g., EM hard and EM local currency or EM and DM mandate). Additionally, several other less popular benchmarks exist by other providers that have similar index construction but are not captured by the survey. As of Q3:2019, JPM survey of local bond funds tracking their indices were close to $\$ 230$ billion.

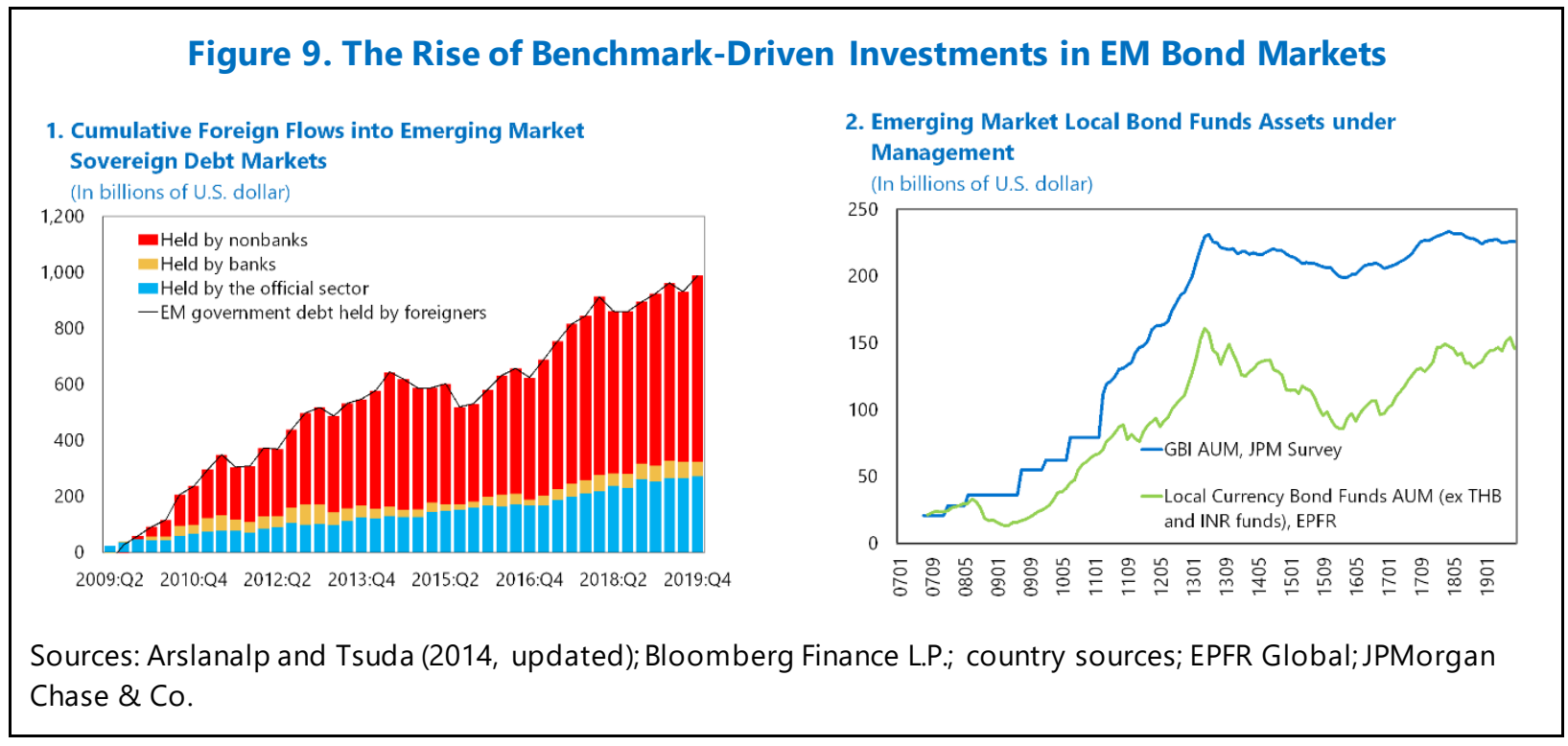

We use two alternative approaches to estimate the size of benchmark driven investments. The first is a regression-based analysis, while the second is based on event studies focused on key index inclusion events in recent years. The two approaches are complementary and result in 
broadly consistent estimates of the size of benchmark-driven investments, suggesting that these stood around $\$ 300$ billion at end-2019, somewhat above survey-based estimates. ${ }^{4}$

\section{A. Regression Analysis}

We obtain regression-based estimates of benchmark-driven investments in EM local bond markets using the approach described in Arslanalp and Tsuda (2015). The approach is based on Ballston and Melin (2013). It assumes that the entire pool of capital invested in EM local markets can be divided into two pools: one benchmarked to the GBI-EM Global Diversified (including only the countries in the index) and the other benchmarked to all EMs (including those outside the index) based on the size/market capitalization of their government bond markets (unconstrained). By looking at the amount allocated to individual markets, one could then estimate the relative proportions of these two pools over time by solving for $a_{t}$ and $b_{t}$ in the following equations:

$$
F_{i t}=a_{\mathrm{t}} \mathrm{w}_{\mathrm{i}, \mathrm{t}}+b_{\mathrm{t}} W_{\mathrm{i}, \mathrm{t}}+\varepsilon_{\mathrm{i}, \mathrm{t}}
$$

Subject to:

$$
a_{\mathrm{t}}+b_{\mathrm{t}}=\sum_{i=1}^{N} F_{i t}
$$

Where $a_{t}$ is the pool of benchmark-driven investments at time t. $b_{t}$ is the pool of unconstrained investors at time t. $w_{i, t}$ is the weight of country $\mathrm{i}$ in the J.P. Morgan GBI-EM Global Diversified index at time $t . W_{i, t}$ is the weight of country i's bond market at time $t$ based on market capitalization. $F_{i, t}$ is the nominal amount of foreign holdings of country i's bonds at time $t$, in U.S. dollars. $\varepsilon_{i, t}$ is the extent to which portfolio managers are over-/underweight country $i$ at time $t$.

The estimation is conducted using a constrained least squares (CLS) approach given that $a_{t}$ and $b_{t}$ should add up to total foreign holdings for each month. The sample covers the period from January 2010 to June 2020 and includes 17 countries (Table 1). Of these 17 countries, 13 are "benchmark" countries (i.e., part of the GBI-EM Global Diversified index for most of the sample period), while 4 are "off-benchmark" (the Czech Republic, India, Israel, and Korea). ${ }^{5}$ The mix of countries provides useful heterogeneity for the estimation of $a_{t}$ and $b_{t}$.

\footnotetext{
${ }^{4}$ Not surprisingly, the regression-based estimates and event studies a re somewhat higher than the J.P. Morgan survey, which only covers a ssets under management that track the J.P. Morgan GBI-EM index- the most widely-used EM local-currency bond index by market participants but not the only one(Annex I). Also, by design, a survey is only a sa mple and not the full universe.

${ }^{5}$ Chile, Dominican Republic, the Philippines, and Uruguay, which are part of the GBI-EM Global Diversified index, are not included in the estimation due to lack of monthly data. They account for a small portion of the index, only 3 percent as of end-2019. Initially, the Czech Republic, Isra el, and Korea were part of the index when it was launched in 2005 but have been out of the index sinceat lea st 2010. The Czech Republic re-entered the index in April 2017. For the period since then, it is considered a "benchmark" country in the estimation.
} 


\begin{tabular}{|cccc|}
\hline \multicolumn{4}{|c|}{ Table 1. Sample of Countries 1/ } \\
\hline Asia & Latin America & EMEA-EU & EMEA-Non EU \\
\hline India & Brazil & Czech Republic & Israel \\
Indonesia & Colombia & Hungary & Russia \\
Korea & Mexico & Poland & South Africa \\
Malaysia & Peru & Romania & Turkey \\
Thailand & & & \\
\hline $\begin{array}{l}\text { 1/ Countries that are not in the GBI-EM Global Diversified index are shown in italics. The } \\
\text { Czech Republic re-entered the index in April 2017. EMEA = Europe, Middle East, and Africa. }\end{array}$
\end{tabular}

The relevant data for the estimation (total outstanding and foreign holdings of local-currency government debt securities) come from national data sources, as discussed in Arslanalp and Tsuda (2014). Figure 10 provides a summary of the data as of end-2019. Figure 11 provides the country weights $\left(w_{i, t}\right.$ and $\left.W_{i, t}\right)$ as of end-2019.

Figure 10. Emerging Market Local-Currency Government Debt Securities, End-2019 1/

(In billions of U.S. dollar)
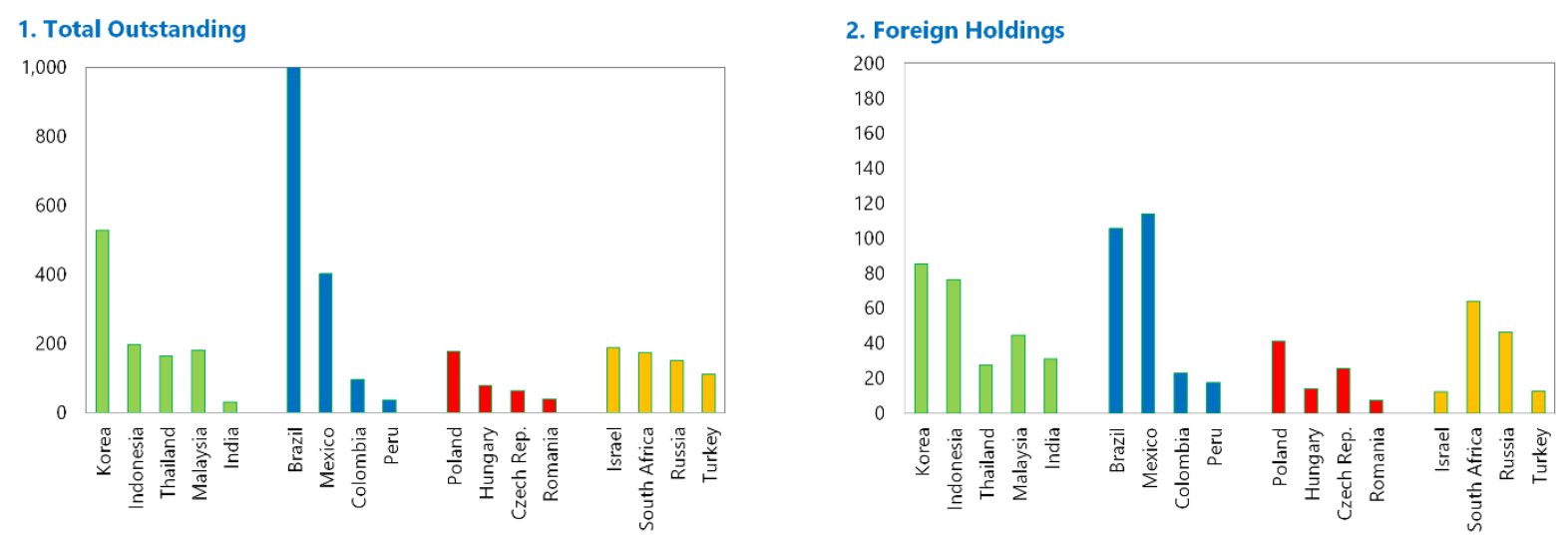

Sources: Arslanalp and Tsuda (2014, updated).

$1 /$ Local-currency central government debt securities. For India, the figure is based on the foreign investment quota. 
Figure 11. Emerging Market Local-Currency Government Debt Markets: Country Weights, End-2019 1/

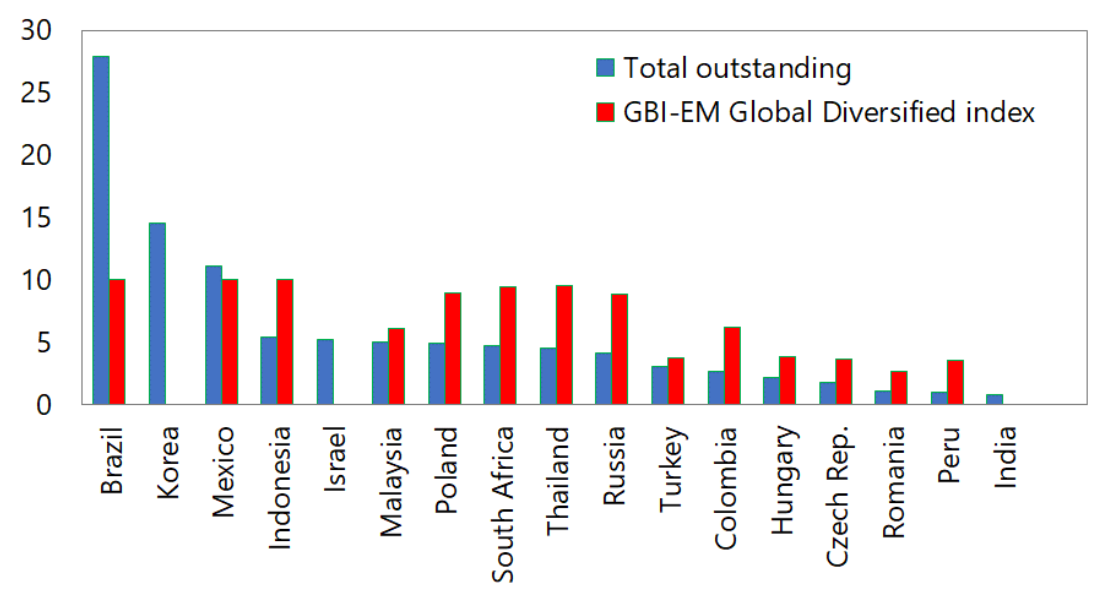

Sources: Arslanalp and Tsuda (2014, updated); and J.P. Morgan.

1/ Local-currency central government debt securities. For India, the figure is based on foreign investment quota.

The results of the regression analysis for $a_{t}$ and $b_{t}$ are summarized in Figure 12. The results suggest that the pool of benchmarkdriven investments in EM local currency debt markets was $\$ 330$ billion at end-2019. The detailed results for 2014-19 are presented in Table 2.

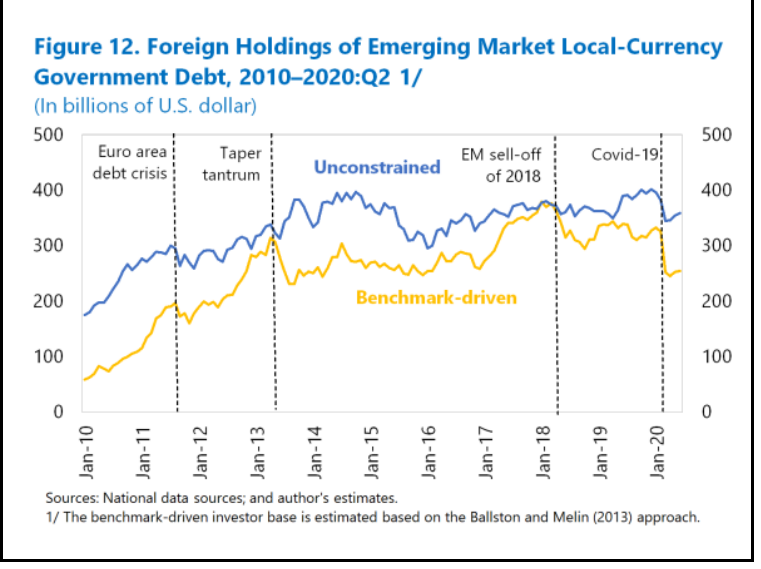

\begin{tabular}{|c|c|c|c|c|c|c|}
\hline & 2014 & 2015 & 2016 & 2017 & 2018 & 2019 \\
\hline$a_{\mathrm{t}}$ & 259.6 & 247.1 & 258.1 & 359.0 & 311.1 & 327.0 \\
\hline t-stat & 4.32 & 4.98 & 4.67 & 8.64 & 8.62 & 7.23 \\
\hline P $>$ t-stat $\mid$ & 0.00 & 0.00 & 0.00 & 0.00 & 0.00 & 0.00 \\
\hline$b_{\mathrm{t}}$ & 367.3 & 318.4 & 339.6 & 365.8 & 362.5 & 400.9 \\
\hline t-stat & 6.11 & 6.41 & 6.14 & 8.80 & 10.05 & 8.86 \\
\hline P $>$ tt-stat $\mid$ & 0.00 & 0.00 & 0.00 & 0.00 & 0.00 & 0.00 \\
\hline F-stat & 37.36 & 41.13 & 37.68 & 77.43 & 100.97 & 78.49 \\
\hline Prob $>F$ & 0.00 & 0.00 & 0.00 & 0.00 & 0.00 & 0.00 \\
\hline \multicolumn{7}{|c|}{ Source: IMF staff estimates. } \\
\hline
\end{tabular}


Figure 13 shows how the composition of foreign investors (between benchmark-driven and unconstrained) have changed over time during 2010-2019 and where they stand across countries as of end-2019 (Annex II provides the country-specific time series). During the three recent episodes of significant capital flow reversals, portfolio flows driven by benchmark investors were less sticky than other types of flows. ${ }^{6}$ The prospect of faster-thananticipated policy normalization by the Federal Reserve in mid-2013 triggered large portfolio outflows driven by emerging-market-dedicated investment funds. Similarly, there were sharp portfolio outflows by emerging market benchmark-driven funds during the 2018 emerging market sell-off (April-August 2018), after almost two years of a steady buildup of their positions in local currency bonds, and the recent COVID-19 related shock in March 2020.

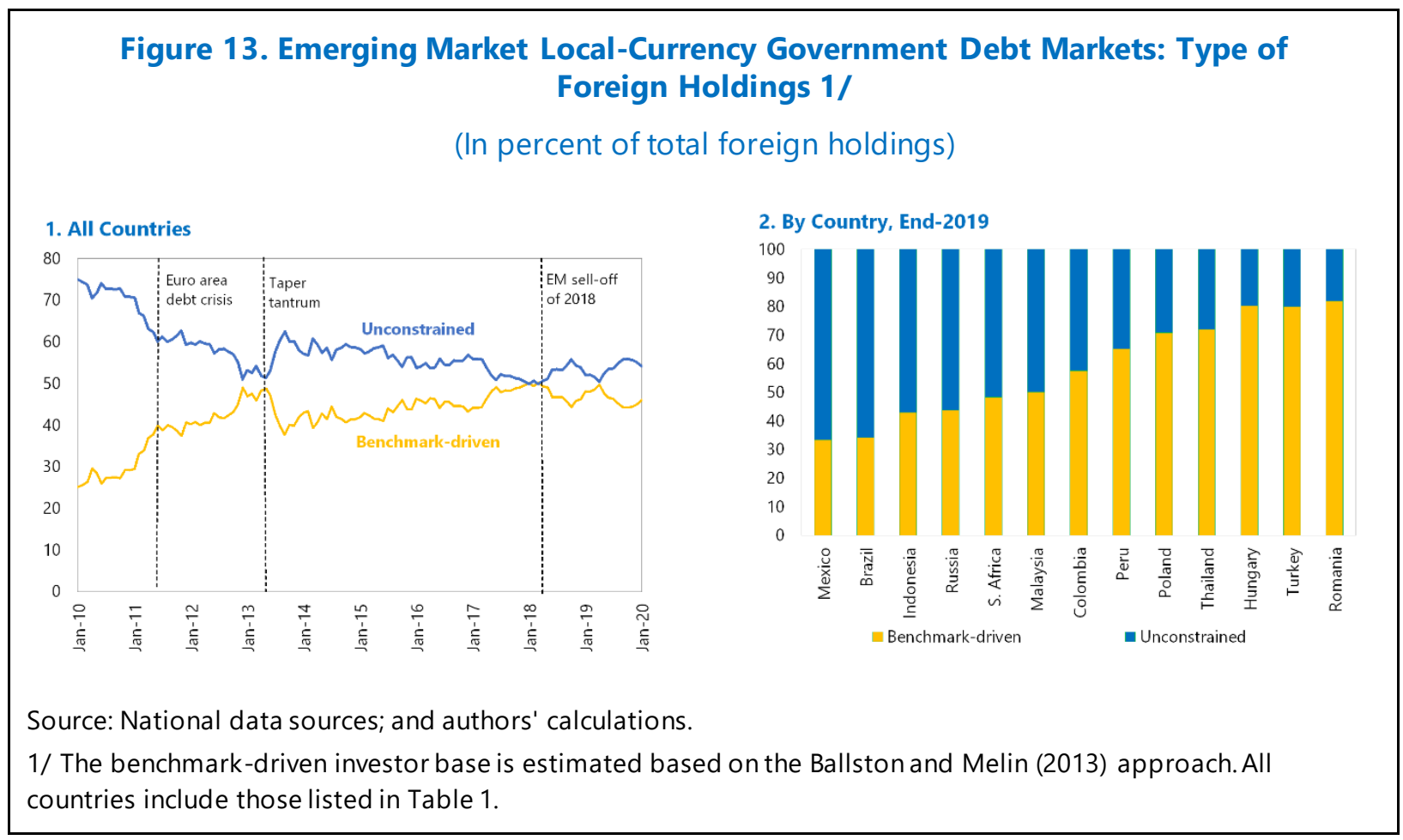

Estimates of benchmark-driven investments also vary significantly across countries (Figure 13, panel 2, Figure 14). As a result, the same kinds of shocks can prompt different capital flow responses in different countries. For instance, Turkey has a high share of benchmark-driven investments as a proportion of the total local currency foreign holdings, but it is relatively small as a percent of GDP. This is in contrast to Hungary where the systemic importance of such investors is much higher.

\footnotetext{
${ }^{6}$ Unconstrained investors include various types such as hedge funds a nd absolute return funds but a lso investors tracking global bond benchmarks. The analysis a ssumes that investors tracking global bond benchmarks do not track emerging markets closely, given that weight of em erging market is small in these indices (see Annex I).
} 


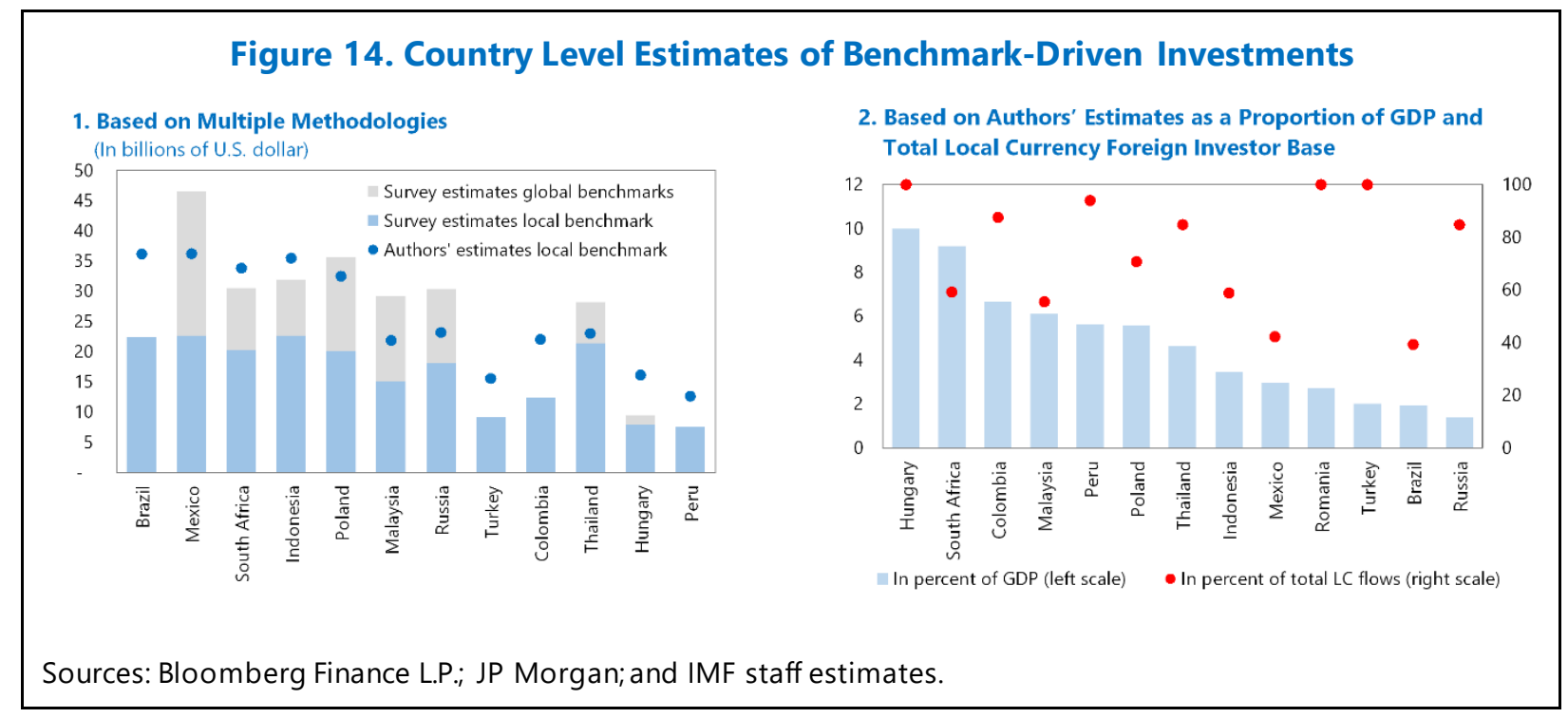

\section{B. Event Studies}

In this section, we present the results of two event studies that provide supporting evidence on the size of benchmark-driven investments. The approach follows Arslanalp and Tsuda (2015). Overall, the event studies suggest that the pool of benchmark-driven investments was around $\$ 370$ billion during the third quarter of 2017 and $\$ 340$ billion during the second quarterly of 2018 , broadly in line with the regression results presented earlier.

The event studies could be based on episodes, in which a country's weight in the J.P. Morgan GBI-EM index rises either due to a country or security inclusion event. When J.P. Morgan adds to the index a new country (country inclusion) or a new set of debt securities for a country already in the index (security inclusion), the country's weight in the index rises. In either case, to track the index, benchmark-driven investors would need to allocate more capital to the country. In contrast, this should not affect unconstrained investors as, by definition, they are not guided by index weights. As a result, such events can create portfolio inflows by benchmark-driven investors, but not unconstrained investors, due to the technical (not fundamental) nature of the event. Arslanalp and Tsuda (2015) examined three security inclusion events (Colombia, Peru, Romania). In this paper, we examine two country inclusion events (Dominican Republic and Uruguay) that took place since 2015.7

A country's weight in the index can change due to valuation effects or inclusion events. For example, Russia's weight in the GBI-EM Global Diversified fell rapidly from 10 percent to 4.7 percent between March 2014 and end-March 2015, mainly due to the sharp drop in the value of the ruble during this period. This highlights the importance of separating valuation effects from exogenous changes in country weights. For that, we use the approach of Raddat and others (2017) to separate the change in a country's index weight $\left(w_{i t}\right)$ into two

\footnotetext{
${ }^{7}$ Country-inclusion events would be an upper bound estimate of BDI, while security inclusion events would be a lower bound, given that country inclusion events may have wider signa ling effects (reflecting changes in a country's capital flow policies/measures) that affect BDI and unconstrained investors simultaneously.
} 
components: (i) the buy-and-hold component, which captures the valuation effects; and (ii) the exogenous component, which captures inclusion events.

$$
w_{i t+1}-w_{i t}=\underbrace{\left(w_{i t+1}-w_{i t} * \frac{R_{i t}}{R_{b t}}\right)}_{\text {Exogenous componentBuy-and-hold component }}+\underbrace{\left(w_{i t} * \frac{R_{i t}}{R_{b t}}-w_{i t}\right)}
$$

Where $w_{i t}$ is the weight of country $\mathrm{i}$ in the J.P. Morgan GBI-EM Global Diversified index at time $t$. $R_{i t}$ and $R_{b t}$ are the total gross returns of country $i$ 's bonds and the benchmark, respectively, from time $t$ to $t+1$. Moreover, as benchmark-driven investments should only respond to the exogenous part of the country weight change, the size of the benchmarkdriven investor base can be estimated as follows:

$$
B_{t}=f_{i t} /\left(w_{i t+1}-w_{i t} * \frac{R_{i t}}{R_{b t}}\right)
$$

Where $B_{t}$ is the benchmark-driven investor base at time $t$ in U.S. dollars. $f_{i t}$ is the net foreign purchases of country i's government bonds between $t$ and $t+1$ in U.S. dollars.

Below, we estimate the benchmark-driven investor base using two country inclusion events that took place during 2017-18. Specifically, we estimate $\left(B_{t}\right)$ in Equation 4 when Uruguay and Dominican Republic were included in the J.P. Morgan GBI-EM Global Diversified index during the third quarter of 2017 and second quarter of 2018, respectively.

\section{Uruguay}

Uruguay joined the J.P. Morgan GBI-EM index during July-September 2017. In June 2017, J.P. Morgan announced that it would include Uruguay in the GBI-EM index over a three-month period (July-September 2017) in a phased manner. As a result, Uruguay's weight in the GBI-EM Global Diversified index rose from zero at end-June 2017 to 0.29 percent at end-September 2017.

To track the index, a benchmark-driven investor would need to allocate capital to Uruguay during this period. Indeed, net foreign inflows into Uruguay's government bonds were exceptionally large when the country was included in the index $-\$ 1$.1. billion over July-September 2017 - the highest quarterly figure recorded in official balance of payments statistics between 2000-17. Based on Equation 4, this would imply a benchmark-driven investor base of around $\$ 370$ billion at the time of the event (Table 3), slightly above the regression results presented in the previous section. 


\begin{tabular}{|lcc|}
\hline \multicolumn{3}{|c|}{ Table 3. Uruguay: Event Study } \\
\hline & End-June & End-Sep \\
& 2017 & 2017 \\
\hline \multicolumn{3}{|c|}{ (In percent) } \\
Country weight (GBI-EM global diversified) & 0.00 & 0.29 \\
Change in country weight & 0.29 \\
Buy-and-hold component & 0.00 \\
Exogenous component (a) & (In billions of U.S. dollar) \\
& & 1.08 \\
Net foreign purchases during Jul-Sep 2017 (b) & 373 \\
Estimated benchmark-driven investor base (c=b/a) & \\
\hline Sources: JP Morgan; national authorities; and author's calculations. \\
\hline
\end{tabular}

\section{Dominican Republic}

The Dominican Republic joined the J.P. Morgan GBI-EM index during April-June 2018. In March 2018, J.P. Morgan announced that it would include the Dominican Republic in the GBI-EM index over a three-month period (April to June 2018) in a phased manner. As a result, Dominican Republic's weight in the GBI-EM Global Diversified index rose from zero at end-March 2018 to 0.10 percent at end-June 2018.

To track the index, a benchmark-driven investor would need to allocate capital to the Dominican Republic during this period. Indeed, net foreign inflows into Dominican Republic's government bonds were exceptionally large when the country was included in the index — \$340 million over April-June 2018 - the highest quarterly figure recorded in official balance of payments statistics between 2011-18. Based on Equation 4, this would imply a benchmark-driven investor base of around $\$ 340$ billion at the time of the event (Table 4 ), fully in line with the regression results presented in the previous section. 


\begin{tabular}{|lcr|}
\hline \multicolumn{3}{|c|}{ Table 4. Dominican Republic: Event Study } \\
\hline & End-Mar & End-Jun \\
& 2018 & 2018 \\
\hline \multicolumn{3}{|c|}{ (In percent) } \\
Country weight (GBI-EM global diversified) & 0.00 & 0.10 \\
Change in country weight & 0.10 \\
Buy-and-hold component & (In billions of U.S. dollar) \\
Exogenous component (a) & 0.00 \\
& & 0.10 \\
Net foreign purchases during Apr-Jun 2018 (b) & 339 \\
Estimated benchmark-driven investor base (c=b/a) & \\
\hline Sources: JP Morgan; national authorities; and author's calculations. \\
\hline
\end{tabular}

\section{How SENSITIVE ARE BENCHMARK-DRIVEN INVESTMENTS TO GLOBAL FACTORS?}

In this section, we examine the sensitivity of benchmark-driven investments to global factors, focusing on the dynamics of portfolio flows to emerging markets. It is worth highlighting that the literature has generally relied on data reported by fund managers for the purpose of analyzing the effect of benchmarks on portfolio flows. In this literature, flows into investment funds ("fund flows") are often used synonymously with (portfolio) capital flows, even though they are quite different conceptually (Koepke, 2019). Koepke and Paetzold (2020) argue that studies using fund flows data as a proxy for portfolio flows are likely to overstate the importance of external drivers, precisely because fund flows are subject to benchmark effects.

In the context of financial intermediation by investment funds, it is useful to distinguish three levels of decision-making that can give rise to a portfolio flow to a country: ${ }^{8}$

(1) Decisions by ultimate investors to purchase/sell shares of an investment fund (prompting the fund managers to buy/liquidate securities). Ultimate investors typically treat emerging markets as an asset class, focusing on factors that affect emerging markets as a group, rather than on country-specific factors (Bush and others 2019). Such external developments include interest rates in advanced markets or global risk appetite.

(2) Decisions by the fund manager to change the portfolio allocation relative to the relevant benchmark index. This second level of decision-making is where country-specific factors play an important role (Bush and others 2019). The rise of benchmark-driven investments

\footnotetext{
${ }^{8}$ As a caveat, note that none of these decisions will necessarily result in a portfolio flow as measured in the ba lance of payments. This is because the counterparty to a ny investment fund's transactions may also be a resident of the country where the investment fund is domiciled, such that there is no change in cross-border asset holdings at the country level.
} 
means that allocation decisions at the fund manager level are becoming less important, diminishing the role of pull factors.

(3) Decisions by the index provider to change the country weights in the index. This could be due to the inclusion/exclusion of a country's securities in the index that reduces/increases the weights of other countries in the index (triggered for example by a change in a country's credit rating). Such changes may result in portfolio flows that are typically unrelated to traditional push or pull factors (Raddatz and others 2017).

Our empirical approach is adapted from Koepke (2019) and is consistent with the empirical literature, which emphasizes the importance of both external "push" and domestic "pull" factors. We use monthly data from January 2010 to December 2018. The data source for the analysis is the EPFR's fund flows into EM-dedicated bond funds as a proxy for benchmark-driven bond flows to EMs. For comparison, the model is also estimate with overall bond flows to EMs, based on data compiled by the IIF and consistent with official balance of payments statistics from national authorities. ${ }^{9}$

The estimated equation is as follows:

$$
\text { Flows }_{t}=\alpha_{0}+\alpha_{1} \cdot \text { Flows }_{t-1}+\beta \cdot \text { Ris }_{t}+\gamma \cdot \text { Rates }_{t}+\delta \cdot \text { Domestic }_{t}+\varepsilon_{t}
$$

Where Flows $s_{t}$ is the EPFR Global flows into EM dedicated bond funds as a proxy for benchmark-driven bond flows to EMs. $\alpha_{0}$ is a constant term. $\alpha_{1}$ is the coefficient for the lagged dependent variable. $R i s k_{t}$ is a proxy for global risk aversion, measured by the U.S. corporate BBB spread over U.S. Treasury securities and Rates $s_{t}$ is the 10 -year U.S. Treasury yield. ${ }^{10}$ Finally, Domestic $c_{t}$ is a pull variable, namely the emerging market (EM) economic surprise index compiled by Citigroup. The surprise index measures how strong recent economic data releases have been relative to investor expectations, thus providing a proxy for news about economic activity in emerging markets.

The results suggest that benchmark-driven flows are highly sensitive to global factors (Table 5). Flows driven by emerging market benchmarks are about three to five times more sensitive to global risk factors than the balance of payments measures of portfolio flows. For example, a one standard deviation increase in the VIX on average reduces invested assets of benchmark-driven EM investors by 2 percent, compared with $1 / 2$ percent for total portfolio investment (Figure 15, panel 1). Similarly, a one standard deviation increase in U.S. 10-year Treasury yields reduces invested assets by $1 \frac{1}{2}$ percent, compared with about $1 / 4$ percent for total portfolio investment. Furthermore, the sensitivity of benchmark-driven flows to external factors has increased in recent years (Figure 15, panel 2). ${ }^{11}$ Finally, a breakdown of EPFR

\footnotetext{
${ }^{9}$ It is worth noting that EPFR's fund flows data a re conceptually different from BoP-based portfolio flows data and subject to various measurement issues (see Koepke 2019).

${ }^{10}$ As a robustness check, we also use the VIX index a s a n alternative measure of global risk aversion and the three-year-ahead expected federal funds ra te in the Eurodollar market as an alternativemeasure of ra tes.

${ }^{11}$ This is in line with the findings of Goel and others (2019) which show that theEM outflows in responses to global shocks have increased significantly since 2013 .
} 
data in ETFs and mutual funds suggest that ETFs are significantly more sensitive to interest rate and risk aversion shocks than mutual funds (Figure 15, panel 3). This is consistent with studies suggesting that ETFs amplify the global financial cycle in emerging markets (e.g., Converse, Levy-Yeyati, Williams, 2020).

Figure 15. Sensitivity of Flows to External Factors

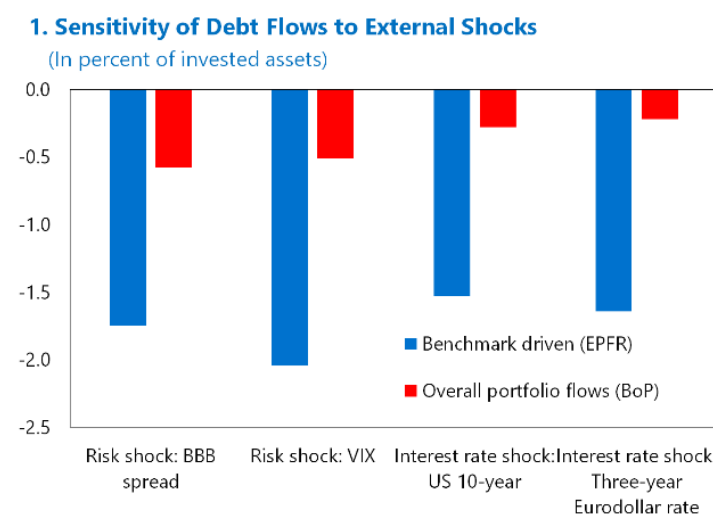
2. Sensitivity of Benchmark-Driven Debt Flows to
External Factors

(In percent of invested assets, based on 36-month rolling regression window)

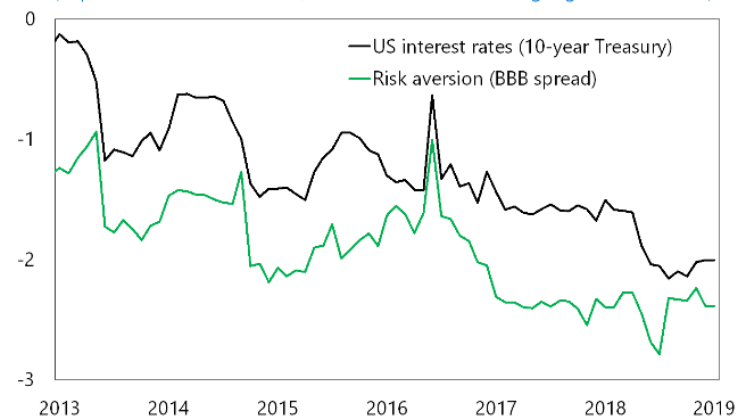

3. Sensitivity of Bond ETFs and Mutual Funds to External Shocks

(In percent of invested assets)

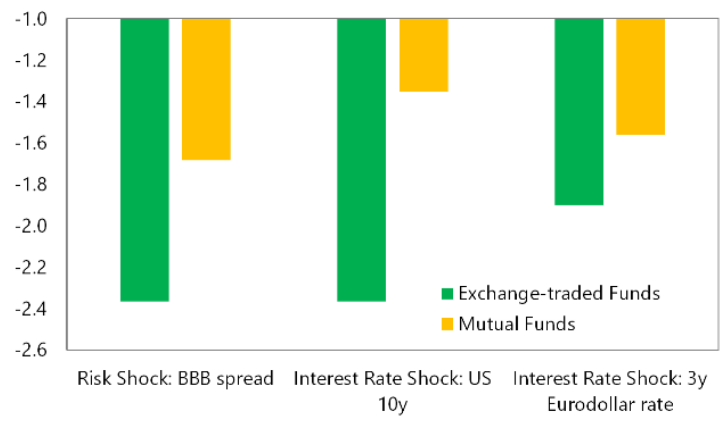

Sources: Bloomberg L.P.; EPFR; Haver Analytics; IIF; IMF staff calculations. 
Table 5. Regression Results on Sensitivity to Global Factors

\begin{tabular}{|c|c|c|c|c|}
\hline \multirow[b]{2}{*}{ Variables } & \multicolumn{2}{|c|}{ Exercise I } & \multicolumn{2}{|c|}{ Exercise 2} \\
\hline & Benchmark flows & BOP flows & Benchmark ETFs & Benchmark MFs \\
\hline \multicolumn{5}{|c|}{ Regression Set 1: Flows = f(Lagged Flows, US BBB spread, US 10yr yields, EM Surprise) } \\
\hline \multirow[t]{2}{*}{ Constant } & 0.22 & $0.89 * * *$ & $1.38 * * *$ & 0.17 \\
\hline & $(0.15)$ & $(0.16)$ & $(0.34)$ & $(0.14)$ \\
\hline \multirow{2}{*}{ Lagged Flows } & $0.58 * * *$ & $0.34^{* * *}$ & $0.23 * * *$ & $0.61 * * *$ \\
\hline & $(0.07)$ & $(0.09)$ & $(0.08)$ & $(0.07)$ \\
\hline \multirow[t]{2}{*}{ Change in U.S. corporate BBB spread } & $-7.60 * * *$ & $-3.96 * * *$ & $-18.92 * * *$ & $-6.84 * * *$ \\
\hline & $(1.55)$ & $(1.22)$ & $(3.35)$ & $(1.53)$ \\
\hline \multirow[t]{2}{*}{ Change in U.S. 10-year yields } & $-2.43 * * *$ & -0.83 & $-8.02 * * *$ & $-2.05 * *$ \\
\hline & $(0.8)$ & $(0.65)$ & $(1.73)$ & $(0.78)$ \\
\hline \multirow[t]{2}{*}{ Change in EM Surprise Index } & -0.01 & 0.00 & -0.02 & 0.00 \\
\hline & $(0.01)$ & $(0.01)$ & $(0.02)$ & $(0.01)$ \\
\hline R-squared & 0.59 & 0.27 & 0.42 & 0.58 \\
\hline Adjusted R-squared & 0.57 & 0.24 & 0.39 & 0.56 \\
\hline F-statistic & 33.20 & 8.68 & 16.74 & 32.72 \\
\hline Included Observations & 99 & 99 & 99 & 99 \\
\hline \multicolumn{5}{|c|}{ Regression Set 2: Flows = f(Lagged Flows, VIX Index, Eurodollar Rates, EM Surprise) } \\
\hline \multirow[t]{2}{*}{ Constant } & 0.21 & $0.80 * \star \star$ & $1.32 * \star *$ & 0.17 \\
\hline & $(0.14)$ & $(0.17)$ & $(0.36)$ & $(0.13)$ \\
\hline \multirow[t]{2}{*}{ Lagged Flows } & $0.71 * \star \star$ & $0.45^{\star * *}$ & $0.37 \star \star \star *$ & $0.72 * * *$ \\
\hline & $(0.06)$ & $(0.09)$ & $(0.08)$ & $(0.06)$ \\
\hline \multirow[t]{2}{*}{ Change in VIX } & $-0.24 * * *$ & $-0.09 * * *$ & $-0.40 * * *$ & $-0.23 * * *$ \\
\hline & $(0.04)$ & $(0.03)$ & $(0.09)$ & $(0.04)$ \\
\hline \multirow[t]{2}{*}{ Change in Eurodollar Rates } & $-1.96 * * *$ & -0.49 & $-4.84 * * *$ & $-1.78 * * *$ \\
\hline & $(0.54)$ & $(0.47)$ & $(1.33)$ & $(0.53)$ \\
\hline \multirow[t]{2}{*}{ Change in EM Surprise Index } & -0.01 & 0.00 & -0.03 & -0.01 \\
\hline & $(0.01)$ & $(0.01)$ & $(0.03)$ & $(0.01)$ \\
\hline R-squared & 0.64 & 0.26 & 0.35 & 0.64 \\
\hline Adjusted R-squared & 0.63 & 0.22 & 0.32 & 0.63 \\
\hline F-statistic & 42.46 & 8.10 & 12.70 & 42.14 \\
\hline Included Observations & 99 & 99 & 99 & 99 \\
\hline
\end{tabular}

Sources: Bloomberg L.P.; EPFR; and Haver Analytics.

1/ Exercise 1 corresponds to Figure 15, panel 1 and Exercise 2 corresponds to Figure 15, panel 3. 
The heightened sensitivity of benchmarkdriven investments to external factors is also observed in the correlation of bond yields across countries after index inclusion events. An analysis of 10-year local bond yields for Chile, Colombia and Czech Republic over the last five years suggests that local bond yields become more correlated after country (or security) inclusion events. Specifically, we find that the 3-month correlation of the country yields with the overall J.P. Morgan GBI-EM yield increases significantly from

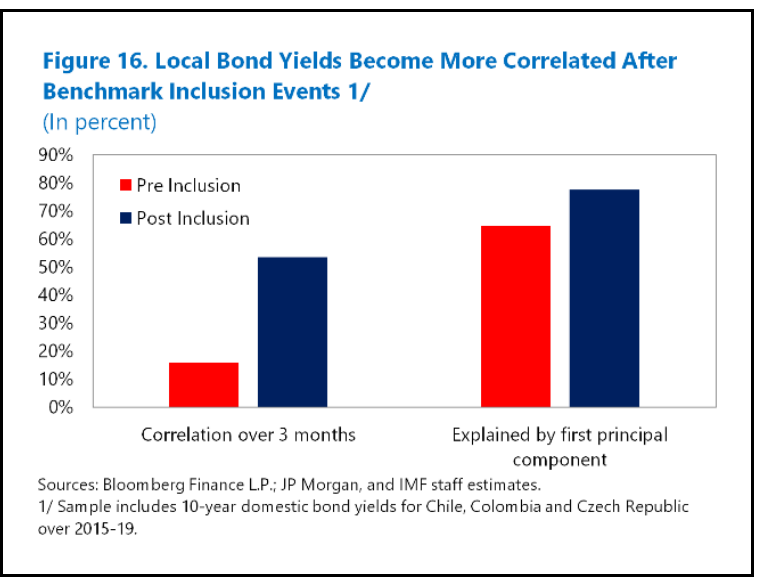
16 percent to 53 percent after inclusion events (Figure 16). ${ }^{12}$ We also calculate the variation explained by the first principal component for our sample countries, which increases from 64 percent to 78 percent post inclusion. These results suggest that the importance of common factors rises as a result of a country's inclusion in a benchmark index.

\section{Conclusion}

In this paper, we take stock of the rise of benchmark-driven investments in emerging markets. We show that assets under management of benchmark-driven investment vehicles have increased rapidly over the past decade. As of end-2019, the size of benchmark-driven investments in EM local currency sovereign bonds is estimated between $\$ 300$ billion, about 40 percent of the foreign investor base.

The changing investor landscape entails both benefits and risks for EMs. On the upside, the inclusion in major benchmark indices provides countries with access to a larger and more diverse pool of external financing. Moreover, capital flows become less sensitive to domestic economic developments, which may reduce outflows in response to domestic shocks. On the downside, growing assets under management of passive and weakly active investment funds boost the role of external drivers, making emerging markets more susceptible to swings in global financial conditions. Empirical results show that benchmark-driven flows are about three to five times more sensitive to global risk factors than total portfolio flows. These benefits and risks are likely to increase as the transition towards passive investing continues through the rise of index funds and ETFs and as mutual funds follow benchmarks more closely to cut costs and increase transparency to remain competitive.

Some of the risks arising from the rise of benchmark-driven investments are exacerbated by the way indices are constructed. As a result of index construction, some countries, often smaller and medium sized EMs, are disproportionately exposed to benchmark-driven investments. Countries with high shares of benchmark-driven investments in local bond markets include, for example, Colombia, Hungary and Peru.

\footnotetext{
${ }^{12}$ The results are corroborated when we take a 6-month correla tion, though to a lesser extent. This suggest that there may be an immediate im pact after inclusion events, which is partially normalized over time
} 
With the importance of benchmark-driven portfolio flows increasing, a close dialogue is needed between index providers, the investment community, and regulators. Enhanced transparency by index providers, such as on eligibility criteria for index inclusion and advance communication of forthcoming index changes, can help promote greater consistency and less flow volatility. Issuers should strive for index inclusion where prudent and avoid introducing fragmentation and concentration risks by premature or partial inclusion of debt instruments in international bond indices.

These finding have important implications for policymakers. As the amounts of passive and benchmark-driven investments rise, index membership may become not only a benefit, but also a source of vulnerability for some emerging markets. Authorities should monitor risks related to the foreign ownership of local currency bonds, especially when a large share of these bonds is held by benchmark-driven investors. They should also consider the potential effects of policy actions on index eligibility, for example from the imposition of capital flows management measures. Given increased sensitivity of benchmark-driven investments to external factors, countries should reduce external vulnerabilities and strengthen buffers by reducing excessive external liabilities, reliance on short-term debt, while maintaining adequate fiscal buffers and foreign exchange reserves. 


\section{REFERENCES}

Arslanalp, S., and T. Tsuda, 2014, "Tracking Global Demand for Emerging Market Sovereign Debt,” IMF Working Paper No. 14/39 (Washington: International Monetary Fund).

— , 2015, "Emerging Market Portfolio Flows: The Role of Benchmark-Driven Investors," IMF Working Paper No. 15/263 (Washington: International Monetary Fund).

Balston, M., and L. Melin, 2013, "Foreign Demand for EM Local Currency Debt," in Deutsche Bank EM Monthly: Diverging Markets, pp. 57-60, Deutsche Bank Market Research (December).

Bernanke, Ben, Mark Gertler, and Simon Gilchrist, 1994, "The Financial Accelerator and the Flight to Quality," NBER Working Paper No. 4789 (Cambridge, Massachusetts: National Bureau of Economic Research).

Broner, F., G. Gelos, and C. Reinhart, 2006, "When in Peril, Retrench: Testing the Portfolio Channel of Contagion," Journal of International Economics, Vol. 69, Issue 1, pp. 203-30.

Bush, Georgia, Carlos Canon, and Daniel Gray, 2019, "Emerging Market Capital Flows: The Role of Fund Manager Portfolio Reallocation," mimeo. Available via the Internet: https://static1.squarespace.com/static/565e4794e4b0d50dfc8d6940/t/5dd754c624218 05afa71b15c/1574393034387/BushCanonGray 21112019.pdf.

Cerutti, E., S. Claessens, and D. Puy, 2019, "Push Factors and Capital Flows to Emerging Markets: Why Knowing Your Lender Matters More Than Fundamentals," Journal of International Economics, forthcoming.

Chen, Sally; D. Drakopoulos and R. Goel, 2019, "China Deepens Global Finance Links as It Joins Benchmark Indexes,” IMF Blog, (Washington: International Monetary Fund).

Converse, N., E. Levy-Yeyati, and T. Williams, 2020, "How ETFs Amplify the Global Financial Cycle in Emerging Markets," International Finance Discussion Papers No. 1268, January (Washington: Board of Governors of the Federal Reserve System).

Coval. J., and E. Stafford, 2007, “Asset Fire Sales (and Purchases) in Equity Markets," Journal of Financial Economics, Vol. 86, No. 2, pp.479-512.

Cremers, M, and A. Petajisto, 2009, "How Active is Your Fund Manager? A New Measure That Predicts Performance," Review of Financial Studies, Vol. 22, No. 9, pp. 3329-65. 
Ferri, Giovanni, Li-gang Liu, and Joseph E. Stiglitz, 2003, "The Procyclical Role of Rating Agencies: Evidence from the East Asian Crisis," Economic Notes, Vol. 28, pp. 335-55.

Goel, Rohit, R. Koepke, F. Natalucci, E. Papageorgiou, and J. Williams, 2019, "IndexInclusion Risks for Emerging Markets," OMFIF Public Report (London, United Kingdom: Official Monetary and Financial Institutions Forum).

International Monetary Fund, 2019, Global Financial Stability Report: Vulnerabilities in a Maturing Credit Cycle, pp. 31-37, Washington, April.

—_, 2020, Global Financial Stability Report: Markets in the Time of COVID-19, Washington, April.

Jotikasthira, Chotibhak, Christian Lundblad, and Tarun Ramadorai, 2012, "Asset Fire Sales and Purchases and the International Transmission of Funding Shocks," Journal of Finance Vol. 67, Issue 6, pp. 2015-2050.

J.P. Morgan, 2017, “Index Governance Review,” May 2017.

Kamin, Steven B., John W. Schindler, and Shawna L. Samuel, 2001, "The Contribution of Domestic and External Factors to Emerging Market Devaluation Crises: An Early Warning Systems Approach," International Finance Discussion Paper No. 711 (Washington: Board of Governors of the Federal Reserve System).

Koepke, R., 2019, "What Drives Capital Flows to Emerging Markets: A Survey of the Empirical Literature," Journal of Economic Surveys Vol. 33, No. 2, pp. 516-540.

and Simon Paetzold, 2020, "Capital Flow Data: A Guide for Empirical Analysis and Real-Time Tracking,” IMF Working Paper No. 20/171 (Washington: International Monetary Fund).

Lu, Yinqiu, and Dmitry Yakovlev, 2018, "Instruments, Investor Base, and Recent Developments in the Malaysian Government Bond Market," IMF Working Paper No. 18/95 (Washington: International Monetary Fund).

Miyajima, K. and I. Shim, 2014, "Asset Managers in Emerging Market Economies," BIS Quarterly Review, September (Basel, Switzerland: Bank for International Settlements).

Pandolfi, L., and T. Williams, 2020, "Real Effects of Sovereign Debt Inflow Shocks," AEA Papers and Proceedings, Vol. 110, pp. 511-515. 
Raddatz, C., S. Schmukler, and T. Williams, 2017, "International Asset Allocations and Capital Flows: The Benchmark Effect," Journal of International Economics, Vol. 108, pp. 413-30 (September).

Sienaert, A., 2012, "Foreign Investment in Local Currency Bonds: Considerations for Emerging Market Public Debt Managers," World Bank Policy Research Working Papers No. 6284 (Washington: The World Bank). 


\section{ANNEX I. EMERGING MARKET AND GLOBAL BOND INDICES}

The J.P. Morgan GBI-EM index is the most widely used index for investing in EM local government bonds. There are also global bond indices by Bloomberg-Barclays and FTSE that include several EMs. However, the weight of EMs still remains relatively small in the global bond indices, less than one percent at the country level and four percent at the aggregate level, as of April 2020.

\section{Major EM bond indices}

The J.P. Morgan Government Bond Index-Emerging Markets (GBI-EM) index was launched in 2005. There are three versions of the index (GBI-EM Broad, GBI-EM Global, and GBI-EM), and each version has a diversified overlay. The diversified version places a 10 percent cap for each country to limit concentration risk. According to J.P. Morgan surveys, the GBI-EM Global Diversified is the most popular version used by investorsaccounting for more than 90 percent of assets benchmarked to all six versions of index. The main entry requirement for the index is market accessibility. There are no minimum-rating requirements or explicit market size limits. Bills and inflation-indexed bonds are not eligible for the index (only fixed-rate nominal bonds). As of end-April 2020, 19 countries were included in the GBI-EM Global Diversified index: Brazil, Chile, China, Colombia, Czech Republic, Dominican Republic, Hungary, Indonesia, Malaysia, Mexico, Peru, Philippines, Poland, Romania, Russia, South Africa, Thailand, Turkey and Uruguay.

The Bloomberg-Barclays Emerging Markets Local Currency Government Index was launched in 2008. The main entry requirements are market accessibility and a minimum market capitalization of $\$ 5$ billion. There are no minimum-rating requirements. Nominal fixed-rate bonds and bills are eligible for inclusion, but not inflation-indexed bonds. The index has a large overlap with the J.P. Morgan GBI-EM Global index, covering broadly the same countries, including two additional countries (Israel and Korea) and excluding two countries (Dominican Republic and Uruguay), as of end-April 2020.

The FTSE Emerging Markets Government Bond Index (EMGBI) was launched in 2013. The main entry requirements are market accessibility, minimum market capitalization of $\$ 10$ billion, and minimum rating requirements of $\mathrm{C}$ by Standard \& Poor's and Ca by Moody's. Bills and inflation-indexed bonds are not eligible for the index (only fixed-rate nominal bonds). This index also has large overlap with the J.P. Morgan GBI-EM Global index. As of end-April 2020, the index includes all but three countries in the GBI-EM Global index (Czech Republic, Dominican Republic and Uruguay), all with small weights on the GBI-EM Global index.

\section{Major global bond indices}

The Bloomberg-Barclays Global Aggregate Index (Global AGG) tracks fixed-rate and investment-grade bonds of both developed and emerging markets, with a market capitalization of about $\$ 60$ trillion, as of April 2020. The index was created in 1992 and historical data are available from January 1987. The Treasury sector of the Global Aggregate index tracks central government bonds issued by 37 countries in 24 currency markets, 
representing a total market capitalization of \$32 trillion, as of April 2020. The main entry requirements are: (i) countries must have investment-grade status, based on the middle rating of Fitch, Moody's, and S\&P (or the lower rating when not all ratings are available), and (ii) "a freely traded, convertible currency with a liquid forward market that allows investors to hedge their currency exposure." As of April 2020, 22 EMs have sovereign bonds included in the Bloomberg-Barclays Aggregate index (with country weights shown in parentheses): Indonesia ( 0.5 percent), Mexico ( 0.5 percent), Thailand ( 0.4 percent), Russia ( 0.3 percent), Malaysia (0.3 percent), Poland (0.3 percent), Saudi Arabia (0.2 percent), Chile (0.2 percent), Qatar (0.1 percent), Czech Republic (0.1 percent), Hungary (0.1 percent), India (0.1 percent), Colombia (0.1 percent), Philippines ( 0.1 percent), Peru (0.1 percent), Romania ( 0.1 percent), and Brazil, Morocco, Kazakhstan, Kuwait, South Africa, Uruguay $(<0.05$ percent each).

The FTSE World Government Bond Index (WGBI) tracks fixed-rate and investmentgrade sovereign bonds of both developed and emerging markets, with a market capitalization of \$23 trillion as of April 2020. The index was created in 1986 and historical data are available from December 1984. Main entry requirements are: (i) minimum market capitalization of $\$ 50$ billion, (ii) a domestic long-term credit rating of A-/A3 by S\&P/Moody's, and (iii) no barriers to entry as reflected in policies that "actively encourage foreign investor participation." As of April 2020, there are only three EMs included in the WGBI (with country weights shown in parentheses): Malaysia (0.4 percent), Mexico (0.8 percent) and Poland (0.5 percent).

Table I.1. Summary of Main Characteristics for Major Bond Indices

\begin{tabular}{|c|c|c|c|c|c|c|}
\hline & \multicolumn{3}{|c|}{ Global Bond Benchmarks } & \multicolumn{3}{|c|}{ EM Bond Benchmarks } \\
\hline Index & $\begin{array}{c}\text { Bloomberg-Barclays } \\
\text { Global Aggregate Index } \\
\text { (Global AGG) }\end{array}$ & $\begin{array}{c}\text { Bloomberg-Barclays } \\
\text { US Aggregate Index } \\
\text { (US AGG) }\end{array}$ & $\begin{array}{c}\text { FTSE World } \\
\text { Government } \\
\text { Bond Index (WGBI) }\end{array}$ & $\begin{array}{l}\text { JP Morgan Emerging } \\
\text { Markets Bond Index } \\
\text { (EMBI \$) }\end{array}$ & $\begin{array}{c}\text { JP Morgan } \\
\text { Government Bond } \\
\text { Index-Emerging } \\
\text { Markets (GBI-EM) }\end{array}$ & $\begin{array}{l}\text { JP Morgan } \\
\text { Corporate } \\
\text { Emerging Markets } \\
\text { Bond Index } \\
\text { (CEMBI) }\end{array}$ \\
\hline Relevance to EM & HC and LC Sov and Corp & HC Sov and Corp & $\mathrm{HC}$ and $\mathrm{LC}$ Sov & HC Sov ${ }^{1}$ & LC Sov & HC Corp \\
\hline Minimum Market Size & \multicolumn{2}{|c|}{ No formal minimum² } & Yes & \multicolumn{3}{|c|}{ No formal minimum } \\
\hline Minimum Issue Size & \multicolumn{3}{|c|}{ Yes } & \multicolumn{3}{|c|}{ Yes } \\
\hline Weighting * & \multicolumn{3}{|c|}{ Market Capitalization } & \multicolumn{3}{|c|}{ Modified market capitalization $^{3}$} \\
\hline Rating criteria & \multicolumn{3}{|c|}{ Investment grade rating required as a minimum to remain in index } & \multicolumn{3}{|c|}{ No minimum rating } \\
\hline Other key Criteria & \multicolumn{3}{|c|}{$\begin{array}{l}\text { More demanding criteria that EM indices on local market investability criteria } \\
\text { including settlement and clearing, capital controls and tax regimes. }\end{array}$} & \multicolumn{3}{|c|}{$\begin{array}{l}\text { Bespoke criteria to determine EM status. Less demanding } \\
\text { investability criteria }\end{array}$} \\
\hline Liquidity Criteria & Yes & & Yes & Yes & Yes & \\
\hline Minimum Maturity Criteria & \multicolumn{3}{|c|}{ At least 1yr remaining maturity } & $\begin{array}{c}2.5 \text { years; Exit when } \\
\text { less than } 24 \text { months to } \\
\text { maturity }\end{array}$ & $\begin{array}{c}2.5 \text { years; Exit when } \\
\text { less than } 13 \text { months } \\
\text { to maturity }\end{array}$ & $\begin{array}{l}5 \text { years; Exit when } \\
\text { less than } 13 \text { months } \\
\text { to maturity }\end{array}$ \\
\hline AUM benchmarked to the index $(\mathbf{S})^{4}$ & \multicolumn{3}{|c|}{ About 2 trillion each } & 370 billion & 228 billion & 105 billion \\
\hline Taxes & Clarity on tax regime & $\begin{array}{l}\text { Only fully taxable issues } \\
\text { are eligible }\end{array}$ & No taxes & & $\begin{array}{c}\begin{array}{c}\text { Taxes are okay if it } \\
\text { doesn't impair index } \\
\text { replicability }\end{array} \\
\end{array}$ & \\
\hline $\begin{array}{l}\text { Capital Control and Investment } \\
\text { Restrictions }\end{array}$ & $\begin{array}{l}\text { No capital controls, quotas, } \\
\text { investment restrictions }\end{array}$ & & $\begin{array}{c}\text { No capital controls, } \\
\text { quotas; Sustainable } \\
\text { issuance; transparent } \\
\text { monetary policy }\end{array}$ & & $\begin{array}{c}\text { No capital controls, } \\
\text { quotas, investment } \\
\text { restrictions }\end{array}$ & \\
\hline
\end{tabular}

Sources: Analyst estimates; Bloomberg Finance L.P.; JPMorgan Chase \& $\mathrm{Co}$; MSCl; and IMF staff estimates.

Note: $\mathrm{AUM}=$ assets under management; $\mathrm{EM}=$ emerging market; $\mathrm{EMBI}=$ J.P. Morgan Emerging Market Bond Index; $\mathrm{HC}=$ hard currency; $\mathrm{LC}=$ local currency; corp = corporate; $\mathrm{NA}=$ not applicable; sov = sovereign.

1/ J.P. Morgan's family of EMBI indices also includes state-owned enterprises that are 100 percent owned by the government.

2/ While there is no specified minimum market size for inclusion in these indices, market size is listed as a criterion for determining country eligibility.

3/ The most commonly followed versions of these indices are those labeled "Dive rsified," which use lower weights than would be implied from pure market weights.

4/ J.P. Morgan estimates of assets under management are from surveys and may underestimate the actual amount benchmarked. For nonJ.P. Morgan indices, the amount benchmarked is estimated based on analyst reports. 


\section{ANNEX II. CHINA'S INCLUSION IN BENCHMARK BOND INDICES}

After several years of speculation, China's local currency bonds are being included in major global bond indices, resulting in rebalancing of portfolios (Chen and others, 2019). The renminbi-denominated government and policy bank bonds were added to the BloombergBarclays Global Aggregate Bond index (Global AGG) in April 2019 with a 20-month transition period. With an estimated \$2.0-2.5 trillion tracking the Global AGG index and a final country weight of about 6 percent (after full inclusion), this is expected to bring $\$ 120-150$ billion capital inflows to China by end-2020. Latest data corroborate this trend and suggest the index inclusion may have contributed significantly to nonresident bond flows to China. From April 2019 to April 2020, foreign holdings of Chinese government and policy bank bonds have risen by $\$ 69$ billion (Figure II. 1, left panel).

China's inclusion in the Global AGG index is paving the way for inclusion in other bond indices, which could eventually lead to inflows around $\$ 300$ billion (IMF, 2019). China's bonds were included in J.P. Morgan's GBI-EM Global index in February 2020 with a 10-month transition period that will see the country's weighting rise to the maximum cap of 10 percent. As of April 2020, China has a 2 percent weight in the index. The impact of China's inclusion may be notable for other EMs in the GBI-EM index. Estimates suggest that it may lead to a reduction in EM-dedicated fund allocations of around \$1-3 billion for the other countries in the index, because of the mechanical rebalancing of the index weights. These outflows may be significant for EMs with a relatively high presence of benchmarkdriven investors in their investor base (Figure II.1, right panel). ${ }^{13}$

Figure II. 1. Impact of China's Inclusion in Benchmark Indices
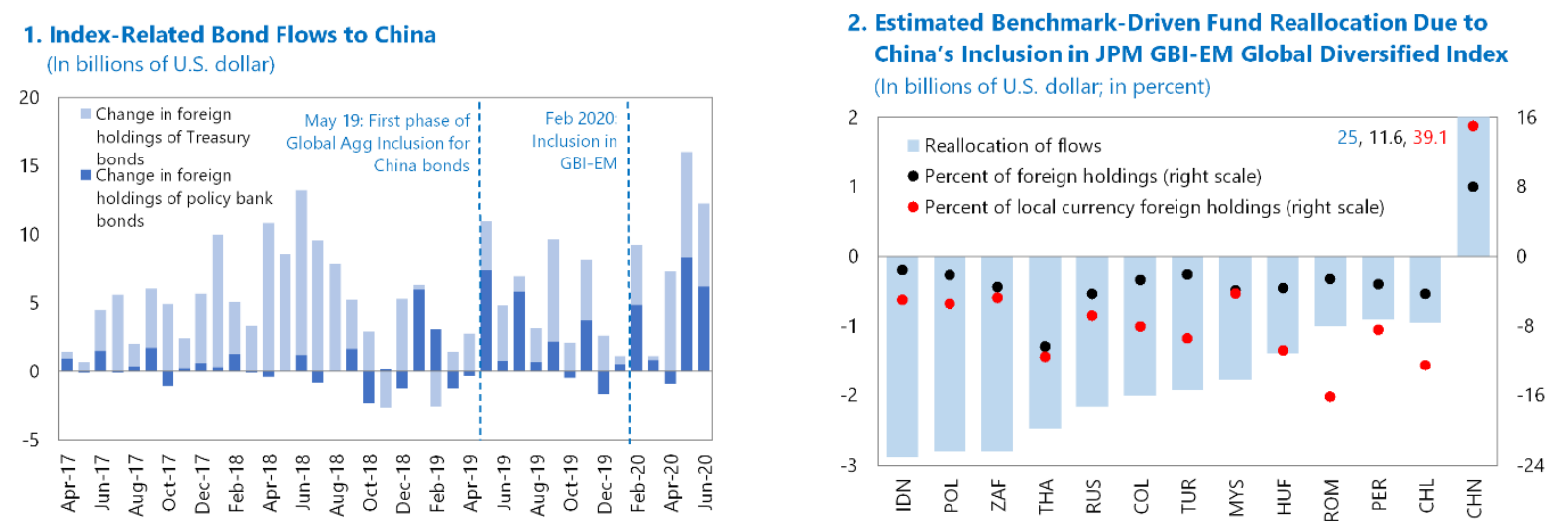

Sources: Bloomberg Finance L.P.; JPMorgan Chase \& Co; and IMF staff estimates.

${ }^{13}$ The mechanical rebalancing of index weights happens gra dually over the transition period. In practice, the rebalancing process may also be more complex. Active fund managers may step in to offset some of the mechanical outflows by benchmarked-driven investors. 
ANNEX III. EM LOCAL CURRENCY GOVERNMENT DEBT: ForEIGN HOLDINGS, 2010-20201/ (In billions of U.S. dollars)

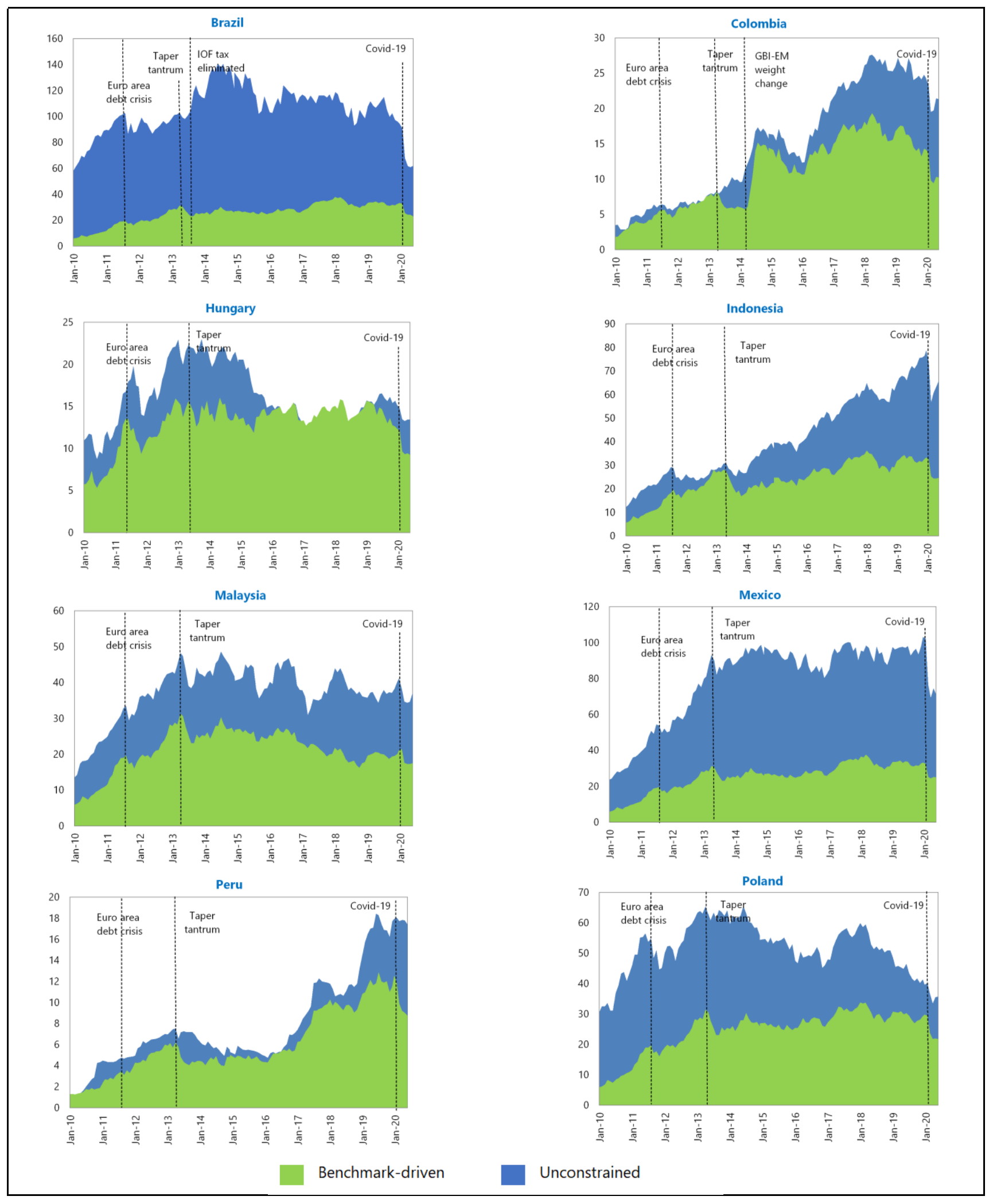




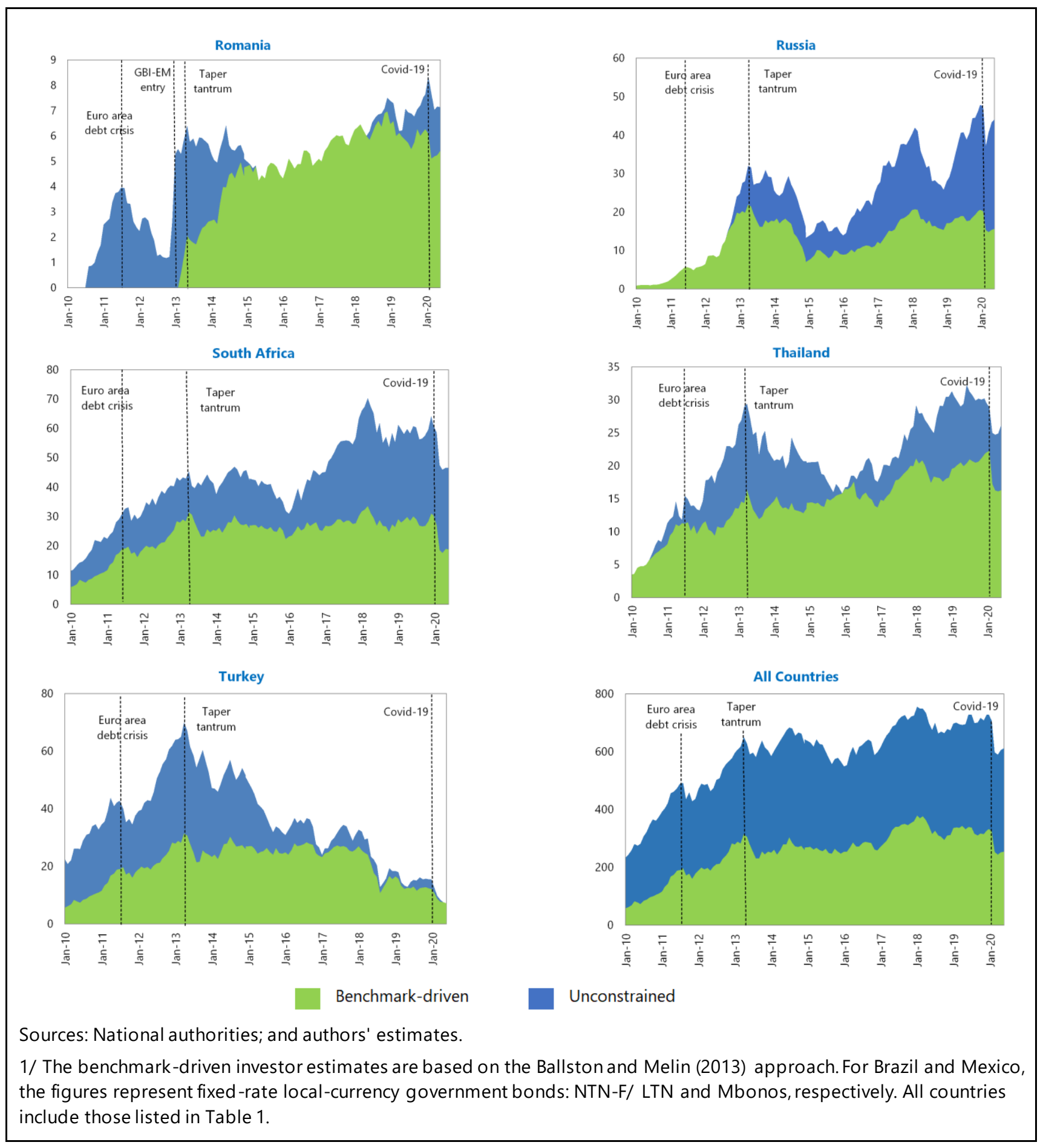

